\title{
A scaling approach to project regional sea level rise and its uncertainties
}

\author{
M. Perrette ${ }^{1}$, F. Landerer ${ }^{2}$, R. Riva ${ }^{3}$, K. Frieler ${ }^{1}$, and M. Meinshausen ${ }^{1}$ \\ ${ }^{1}$ Potsdam Institute for Climate Impact Research (PIK) Telegraphenberg A26, 14412 Potsdam, Germany \\ ${ }^{2}$ Jet Propulsion Laboratory/California Institute of Technology, Pasadena, CA, USA \\ ${ }^{3}$ Dept. Geoscience and Remote Sensing and TU Delft Climate Institute, Delft University of Technology, \\ Delft, The Netherlands
}

Correspondence to: M. Perrette (mahe.perrette@ pik-potsdam.de)

Received: 17 April 2012 - Published in Earth Syst. Dynam. Discuss.: 23 April 2012

Revised: 13 December 2012 - Accepted: 14 December 2012 - Published: 23 January 2013

\begin{abstract}
Climate change causes global mean sea level to rise due to thermal expansion of seawater and loss of land ice from mountain glaciers, ice caps and ice sheets. Locally, sea level can strongly deviate from the global mean rise due to changes in wind and ocean currents. In addition, gravitational adjustments redistribute seawater away from shrinking ice masses. However, the land ice contribution to sea level rise (SLR) remains very challenging to model, and comprehensive regional sea level projections, which include appropriate gravitational adjustments, are still a nascent field (Katsman et al., 2011; Slangen et al., 2011). Here, we present an alternative approach to derive regional sea level changes for a range of emission and land ice melt scenarios, combining probabilistic forecasts of a simple climate model (MAGICC6) with the new CMIP5 general circulation models.

The contribution from ice sheets varies considerably depending on the assumptions for the ice sheet projections, and thus represents sizeable uncertainties for future sea level rise. However, several consistent and robust patterns emerge from our analysis: at low latitudes, especially in the Indian Ocean and Western Pacific, sea level will likely rise more than the global mean (mostly by 10-20\%). Around the northeastern Atlantic and the northeastern Pacific coasts, sea level will rise less than the global average or, in some rare cases, even fall. In the northwestern Atlantic, along the American coast, a strong dynamic sea level rise is counteracted by gravitational depression due to Greenland ice melt; whether sea level will be above- or below-average will depend on the relative contribution of these two factors. Our regional sea level projections and the diagnosed uncertainties provide an improved
\end{abstract}

basis for coastal impact analysis and infrastructure planning for adaptation to climate change.

\section{Introduction}

Since the IPCC Fourth Assessment Report (AR4) (Bindoff et al., 2007), significant progress has been made toward understanding current sea level rise (SLR), in particular with the closure of the sea level budget over the last four decades (Church et al., 2011). However, projections of future SLR are still very uncertain (Lowe and Gregory, 2010; Rahmstorf, 2010). Current coupled model projections can reasonably simulate ocean thermal expansion and the retreat of mountain glaciers and ice caps (MGIC). The evolution of the Greenland and Antarctic ice sheets (GIS and AIS), however, is much less understood (Lowe and Gregory, 2010), mostly due to an incomplete representation of ice-ocean interactions (Murray et al., 2010; Straneo et al., 2010; Pritchard et al., 2012; Hellmer et al., 2012) in ice sheet models.

At the regional level, changes in ocean dynamics and density structure due to water temperature and salinity changes (so-called steric changes) have sizeable effects (Landerer et al., 2007; Pardaens et al., 2010; Yin et al., 2009, 2010). The projected regional distribution of steric SLR is highly non-uniform, and deviations from the global SLR can be similar in magnitude as the global thermal expansion (Yin et al., 2009). The simulated spatial SLR patterns and amplitudes vary considerably across the range of general circulation models (GCMs) (Pardaens et al., 2010). In addition to 
ocean dynamic changes, the melting and dynamic discharge of continental ice is accompanied by an instantaneous adjustment of the Earth's gravity field that causes water to migrate away from dwindling ice masses (Farrell and Clark, 1976). The Earth's shape and rotation vector are also affected and further modulate the pattern of sea level changes. The regional SLR from ice melt hence depends on the spatial distribution of anticipated ice mass losses (Farrell and Clark, 1976; Mitrovica et al., 2001; Bamber and Riva, 2010).

The number and complexity of the processes that influence regional SLR make it challenging to approach the problem in a comprehensive and consistent manner. In particular, gravitational patterns were long absent from syntheses such as the IPCC reports, and have received more attention only recently for projections (Katsman et al., 2008, 2011; Slangen et al., 2011).

Here, we present global estimates of regional SLR towards the end of the 21st century, using the new Representative Concentration Pathways (RCPs) as climate scenarios (Moss et al., 2010). We have designed our method to be flexible with respect to the emission scenarios, and to propagate uncertainties from emissions to regional sea level projections. Traditional analyses of model ensembles for the Special Report on Emissions Scenarios (SRES) climate scenarios (Slangen et al., 2011) rely on a rather small "ensemble of opportunities" provided by GCMs. In contrast, our regional sea level projections are driven by Bayesian projections of global mean temperature and ocean heat uptake from a simple climate model, followed by scaling these with regional "fingerprints" that are derived from the GCMs (see Methods section).

The motivation is two-fold. First, we want to be able to answer policy-relevant questions such as how regional sea level rise may vary between different emission or temperature scenarios, even for intermediate scenarios which have not been simulated by GCMs. Second, we aim at improving the description of uncertainties. Uncertainties in the global mean temperature and ocean heat uptake (determined by climate sensitivity, ocean mixing and radiative forcing) are better represented with observationally constrained ensembles of a simple climate model than with only a handful of GCMs, and are also much faster to run (Allen et al., 2009; Meinshausen et al., 2009). On the other hand, GCMs are the only tools to explore interactions between many climate components at regional or even local scales. Therefore, we effectively decouple uncertainties in the magnitude of warming and in internal physics, in order to better span the overall uncertainty range. Such an approach has been successfully applied to project regional air temperature and precipitation based on global mean temperature (Frieler et al., 2012), or ice sheet surface mass balance from global mean air temperature (Gregory and Huybrechts, 2006; Meehl et al., 2007a). This paper intends to extend the concept to projections of regional sea level rise.

\section{Methods}

We use the reduced complexity carbon cycle-climate model MAGICC6 (Meinshausen et al., 2011) to constrain projections of hemispheric land and ocean temperatures and ocean heat uptake by their historical observations (Brohan et al., 2006; Domingues, 2008), taking into account the range of uncertainties in natural and anthropogenic radiative forcing of the climate system as described in Meinshausen et al. (2009). The projections are based on the new RCP scenarios as used in the fifth IPCC report to cover a broad range of future emissions. RCP 8.5 is comparable with A1FI from IPCC AR4, while RCP 4.5 and RCP 6.0 resemble B1 and A1B, respectively (Moss et al., 2010).

Our general approach is to use probabilistic projections of the global mean contribution of each SLR component to scale the associated spatial patterns (the so-called "fingerprints"). More specifically, we operate in a Monte Carlo framework to combine all uncertainties as described below. The interpretation of our uncertainty estimates is discussed in details in Sect. 2.4.

\subsection{Steric sea level}

In our projections, we distinguish between global mean thermal expansion and the dynamic redistribution of sea level around the mean, as they can have different driving mechanisms. While global mean thermal expansion is the direct result of net ocean heat uptake, dynamic sea level is a dynamic balance between winds, currents and internal density gradients. We therefore separately project both quantities, but our regional steric-dynamic sea level projections are the sum of global mean thermal expansion and dynamic sea level changes. As explained in the following sections, we analysed data of the Coupled Model Intercomparison Project Phase 5 (CMIP5; based on data availability at the time of writing) archive (Taylor et al., 2012) to derive scaling relationships subsequently used with MAGICC6's output. We treat all GCMs as equally likely (see Table S1 in the Supplement for a summary of the 22 GCMs used).

In addition to purely physical air-sea forcing (e.g. wind stress, heat and freshwater fluxes) (Bouttes et al., 2012), many technical choices influence the evolution of sea level in ocean models (Griffies and Greatbatch, 2012). CMIP3 and CMIP5 GCMs use a variety of different configurations and parameterizations for their ocean model components, such as Boussinesq or non-Boussinesq formulations, real surface freshwater or virtual salt fluxes, or different mixing schemes, vertical coordinates and resolutions (Wunsch et al., 2007; Yin et al., 2010). The resulting uncertainties are difficult to quantify in detail due to the computational cost of integrating the models, but they certainly contribute to the spread in the projections. Our ensemble approach aims at synthesizing both kinds of uncertainties: in the forcing and in these different implementations. 

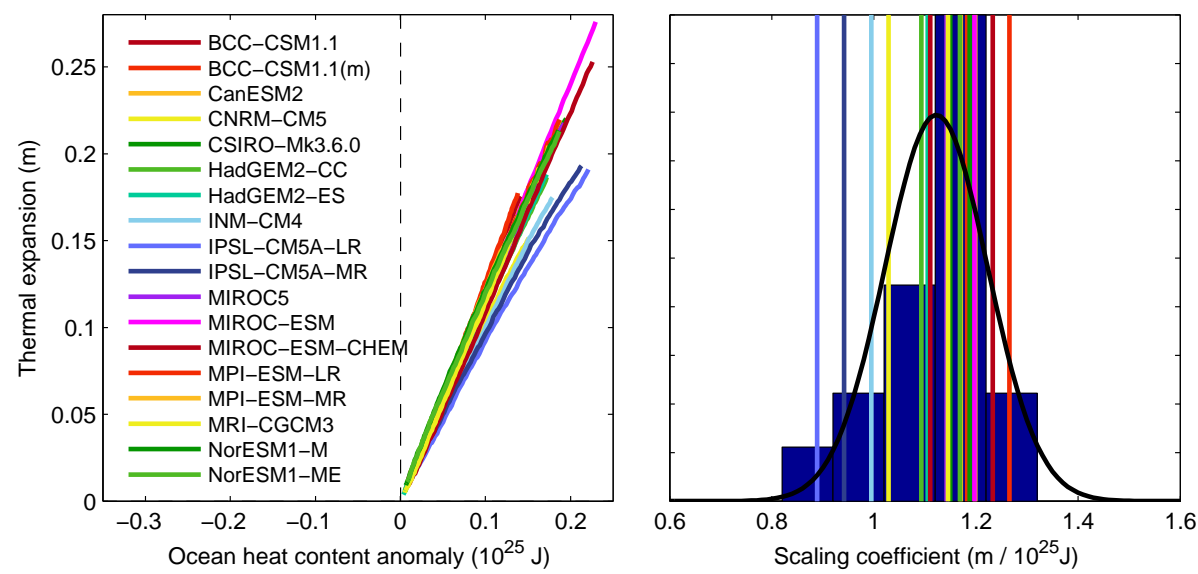

Fig. 1. Left panel: global mean thermal expansion vs. ocean heat content anomaly with CMIP5 GCMs (reference period: 1980-1999) for the 2000-2100 period under the RCP 4.5 scenario (except for MIROC-ESM whose RCP 6.0 scenario is shown); right panel: corresponding regression coefficients (vertical bars) with their empirical frequency distribution and the fitted Gaussian distribution (see Sect. 2.1).

For each emission scenario, we evaluate the relationship between ocean heat content changes and global mean thermal expansion, or between temperature changes and dynamic sea level by linear regression. In this way, we effectively normalize the sea level change by the associated forcing or physical process, thus enabling scenario-independent sea level change projections (provided, of course, that the relationships are to first order linear - see discussion below).

\subsubsection{Global mean thermal expansion}

The global mean ocean heat uptake is well simulated with the MAGICC6 model (Meinshausen et al., 2011, 2009). In order to project global mean thermal expansion, we make use of the quasi-linear relationship between global mean ocean heat content anomaly and thermal expansion as displayed in GCMs (Fig. 1, left panel). We analysed data from 18 GCMs of the CMIP5 archive for which thermal expansion data was available (Table S1 in the Supplement; out of a total of $22 \mathrm{GCMs}$ ) to derive the linear scaling coefficients, based on linear regressions over the 2000-2100 period under the RCP 4.5 scenario, considering anomalies with respect to the 1980-1999 average.

We checked that the scaling coefficients are scenarioindependent: in all RCP scenarios, thermal expansion can be computed from ocean heat content anomalies using scaling coefficients derived from the RCP 4.5 scenario (Table 1 and Fig. S1 in the Supplement). Only for the MIROC-ESM model, the RCP 6.0 scenario was used instead of RCP 4.5, because the latter scenario leads to an anomalously high scaling coefficient (this choice has negligible impacts on the results). The corresponding prediction errors averaged across all models are 4, 0, 0 and $-3 \%$ for the RCPs 3PD, 4.5, 6.0 and 8.5 , respectively (Table 1 ) (calculated for each model and scenario as scaled projection minus direct projection, and normalized by the direct projection).
The scaling coefficients vary slightly among models, most likely because of different depths of heat penetration into the ocean and differences in the background climatological temperature and salinity. We then fit a Gaussian distribution to the derived sample of scaling coefficients (Fig. 1, right panel), thereby assuming that the spread in the sample is random (a Lilliefors normality test with the $18 \mathrm{GCM}$ scaling coefficients confirms that the sample could derive from a normal distribution). The distribution has a mean of $1.12 \times 10^{-25} \mathrm{~m} \mathrm{~J}^{-1}$ and a standard deviation of $0.10 \times 10^{-25} \mathrm{~m} \mathrm{~J}^{-1}$. As a verification, we performed the same analysis with CMIP3 models (not shown) and obtained a very similar distribution of $1.10 \times 10^{-25} \mathrm{~m} \mathrm{~J}^{-1} \pm 0.12 \times 10^{-25} \mathrm{~m} \mathrm{~J}^{-1}$ (we excluded one GCM, CCCMA CGCM 3.1 T47, which had an unrealistically high scaling coefficient of $1.87 \times 10^{-25} \mathrm{~m} \mathrm{~J}^{-1}$ ).

Observation-based estimates of the scaling typically range $1.3-1.6 \times 10^{-25} \mathrm{~m} \mathrm{~J}^{-1}$, which is larger than the GCM-based coefficient (Domingues, 2008). The difference can most likely be reconciled considering the fact that the observational estimates are based on the 0 to $700 \mathrm{~m}$ layer only, whereas our study takes into account the entire depth range (the seawater expansivity is pressure dependent, decreasing with depth). The Gaussian distribution for the scaling parameter is then used in combination with probabilistic MAGICC6 results for ocean heat uptake, a quantity which MAGICC6 can closely emulate (Meinshausen et al., 2011, 2009).

Note that in our analysis, top of atmosphere radiative imbalance was used as a proxy for ocean heat uptake (after removal of a residual imbalance using the pre-industrial control run). Although in the real world a fraction of the heat gained by Earth as a whole goes into land and ice, land and ice heat uptake components are either non-existent or minimal in GCMs. In MAGICC6, only the ocean has thermal 


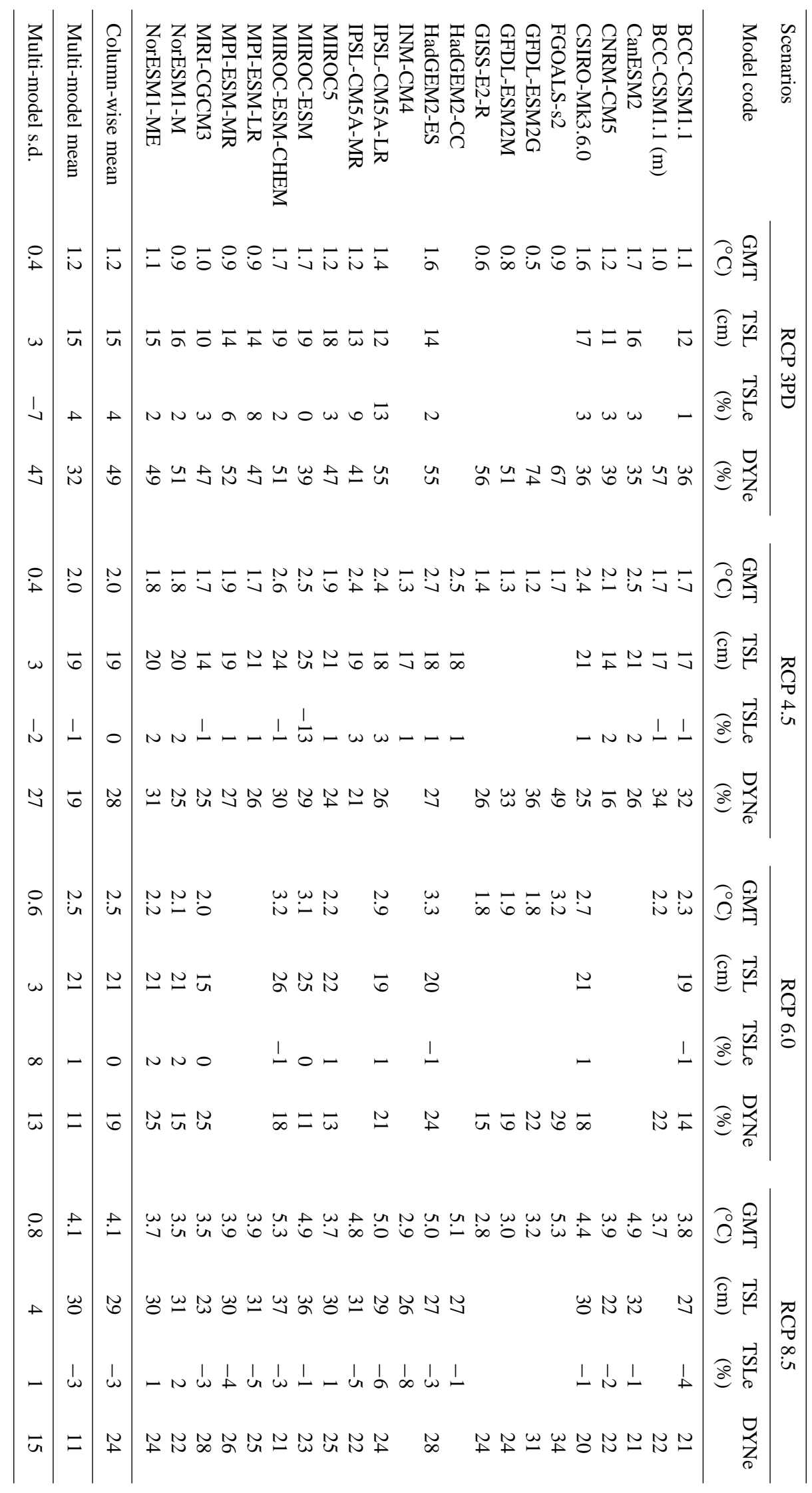

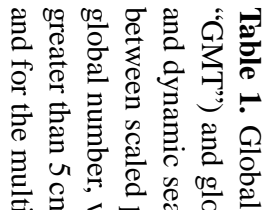
F. 을

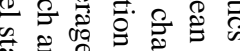

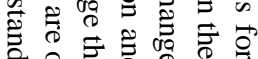

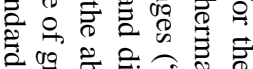

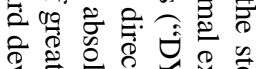

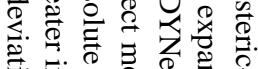

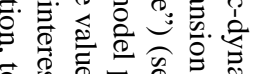
० 0

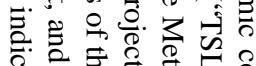

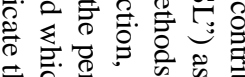
F ० है

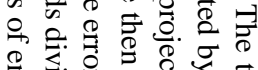
施:

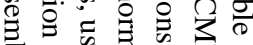

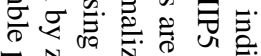

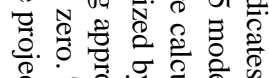

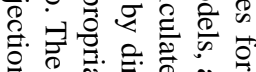
क्ष उ. 密.

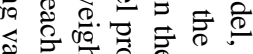

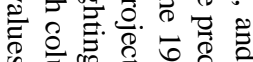
\&

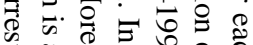

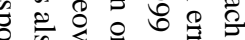

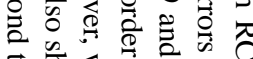

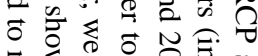
క.

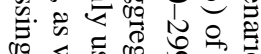

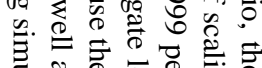
卷

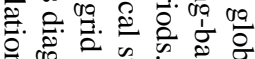

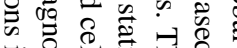

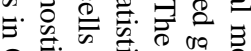

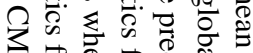

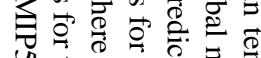

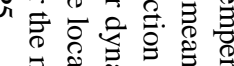

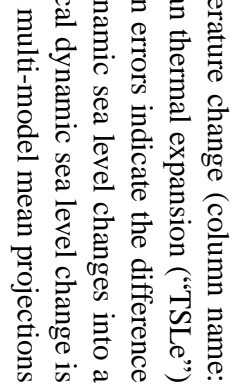


inertia, making ocean heat uptake and top of atmosphere imbalance de facto equal.

\subsubsection{Dynamic sea level changes}

Regional variations of sea level due to ocean density and circulation changes are derived from $20 \mathrm{GCMs}$ from the CMIP5 archive, for which all of the RCP 3PD, RCP 4.5 and RCP 8.5 simulations were available (Table $\mathrm{S} 1$ in the Supplement). For each GCM, a spatial pattern of SLR is derived by linear regression of dynamic sea level changes against global mean temperature (GMT). The regression is performed for each model with all available RCP scenarios as one single data set, over the 2000-2100 period, using yearly temperature and dynamic sea level anomalies relative to $1980-1999$ as the reference period. The patterns of scaling coefficients are then sampled randomly across the available GCM ensemble (assuming each GCM pattern equally likely), and multiplied by MAGICC6's GMT projections under the RCP scenarios. The regressed ocean dynamic patterns are indicated in the Supplement in Fig. S2 in the Supplement.

The relationship between temperature and dynamic sea level changes is illustrated in Fig. 2 in the New York City region. In that region, decadal changes of temperature and dynamic sea level are correlated with an average coefficient $r^{2}=0.56$ (i.e., more than half of the variance is explained by a linear regression). Both the magnitude of the projected sea level change and the skill of the regression are strongly model-dependent. A closer inspection indicates that at this location, most models with a strong dynamic signal (e.g. GFDL models, MPI models and CSIRO-Mk3.6.0) support a linear relationship between dynamic sea level changes and global mean temperature, even though other GCMs (e.g. FGOALS-s2 and HadGEM2-ES) do not. In HadGEM2$\mathrm{ES}$, multi-decadal oscillations seem to dominate the signal, likely related to an instability of the subpolar gyre in that model.

The prediction skill of the scaling approach is shown along various coastlines in Fig. 3, and is quantified on the global domain in Table 1. Corresponding maps are shown in the Supplement (Figs. S3 and S4 in the Supplement). The scaling-based dynamic sea level rise projections (i.e. regressed pattern multiplied by global mean temperature projection from each model) are close to the directly simulated patterns for RCP 6.0 and RCP 8.5 scenarios (19 and $24 \%$ error in average, respectively; Table 1). However, the error is larger for mitigation scenarios such as RCP 3PD and RCP 4.5 , where changes are underestimated by 49 and $28 \%$, respectively, in average. This indicates that dynamic sea levels continue to adjust to climate change even when global temperatures have stabilized. When the multi-model mean is considered, the error against direct model projections is reduced by $8-17 \%$ in all scenarios, but the intermodel spread is still slightly underestimated in RCP 3PD and RCP 4.5 (Table 1; Fig. 3). The generally good agreement of the multi-model mean between temperature-based scaling and direct projections, over a temperature range which varies by a factor of 4 , and despite the above-mentioned shortcomings, supports the use of the regression technique to project century scale, regional dynamic sea level changes in an ensemble context, as a first-order approximation.

In the rest of the manuscript, all 20 "dynamic fingerprints" are used in combination with MAGICC6 temperature projections.

\subsection{Mountain glaciers and ice caps}

\subsubsection{Global mean melt}

The mountain glaciers and ice caps (MGIC) contribution (excluding those near the ice sheets) is computed after Meehl et al. (2007a), itself based on Wigley and Raper (2005). It assumes a global surface mass balance sensitivity, such that the rate of glacier's ice loss is proportional to a change in GMT, $T$ as compared to pre-industrial equilibrium $T_{o}$. It also accounts for a decrease in global surface mass balance sensitivity as the global glacier area decreases, assuming global volume vs. area scaling (Wigley and Raper, 2005):

$\frac{\mathrm{d} V_{\mathrm{gl}}}{\mathrm{d} t}=b_{o}\left(T-T_{o}\right)\left(1-\frac{V_{\mathrm{gl}}}{V_{o}}\right)^{n}$,

where $b_{o}$ is the present (1961-2004 average) global surface mass balance sensitivity, $V_{\mathrm{gl}}$ and $V_{o}$ are the projected and present global glacier volumes (in sea level equivalent) respectively, and $n$ is the scaling coefficient between global glacier area and volume, equal to 1.646 (Wigley and Raper, 2005). Other parameter values and their uncertainty ranges are indicated in Table 2 . These are systematically sampled as part of our Monte Carlo approach, and randomly combined with MAGICC6 projections of global mean temperature change.

The global surface mass balance sensitivity $b_{o}$ and the exponent $n$ are the same as in the IPCC AR4 (Meehl et al., 2007a), while the total glacier volume $V_{o}$ is taken from a more recent estimate (Radic and Hock, 2011). $T_{o}$ is chosen consistently with Eq. (2) (see Sect. 2.3.2) and yields a 19612004 trend of $0.43 \pm 0.12 \mathrm{~mm} \mathrm{yr}^{-1}$, close to IPCC AR4's estimate (Lemke et al., 2007) $\left(0.43 \pm 0.15 \mathrm{~mm} \mathrm{yr}^{-1}\right)$. We did not attempt to tune $T_{o}$ with more up-to-date observational data, since sensitivity tests showed that projections by 2100 are relatively insensitive to the precise specification.

In order to account for mountain glaciers present at the margin of the two main ice sheets, we add, on top of MGIC contribution calculated from Eq. (1), another $+21 \%$ to the Antarctic Peninsula and $+4 \%$ to Greenland, based on a recent model projection (Radic and Hock, 2011).

\subsubsection{Spatial distribution of MGIC melt}

The spatial pattern of sea level rise induced by MGIC melt depends on the spatial distribution of the melt sources, and 


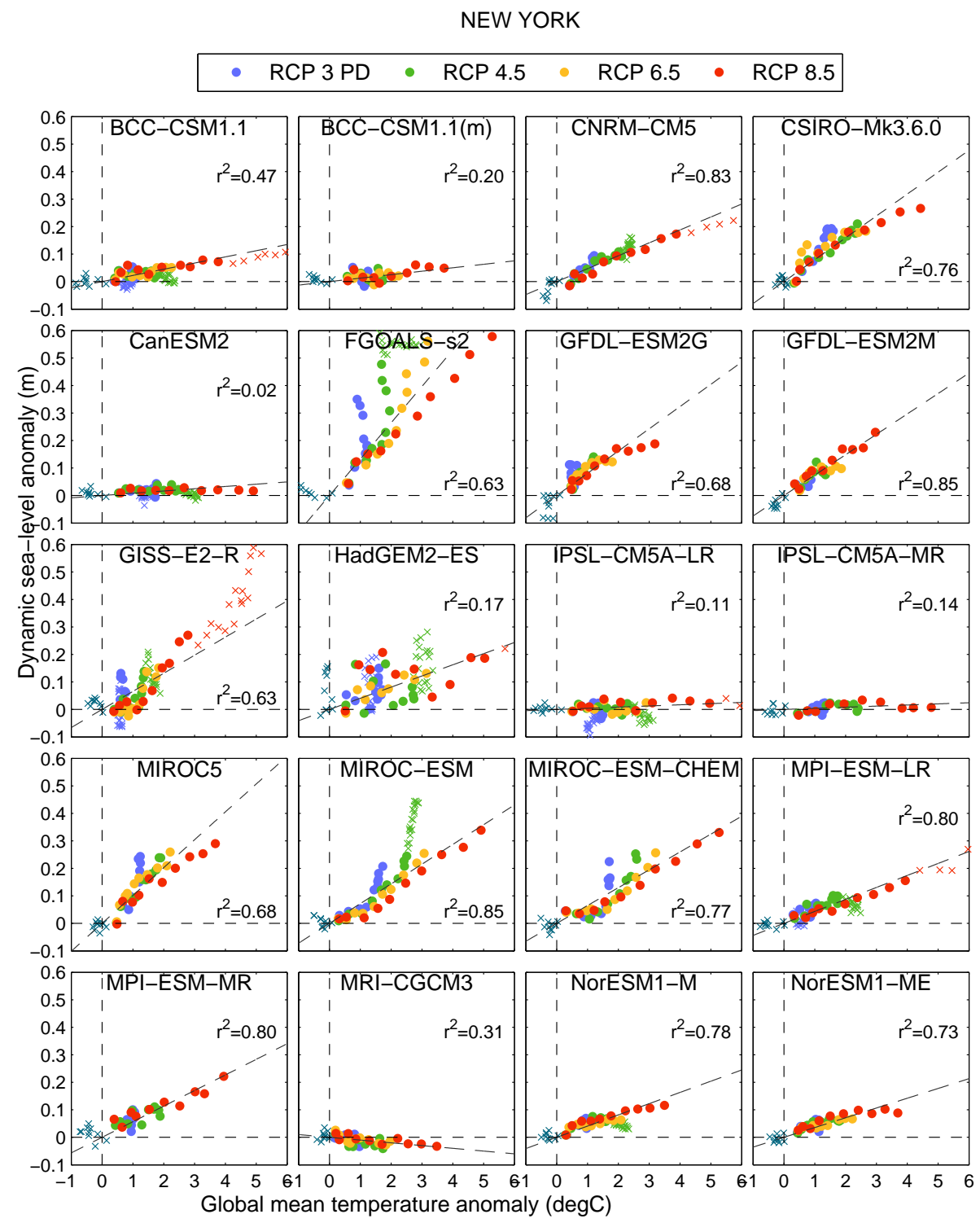

Fig. 2. Scatter plot of dynamic sea level change for New York City against the global mean surface air temperature anomaly (with respect to a 1980-1999 reference period; marker are 10-yr averages). The data represent the historical period (light blue crosses) and the four RCP scenarios (see legend). Stabilization periods (after 2100) are indicated with green crosses. During the stabilization period, the linear relationship between dynamic sea level change and global mean temperature is less robust, but this does not affect our projections towards the end of the 21 st century. The dotted line is the linear regression over 2000-2100 based on all combined RCP scenarios, using yearly values. The $r^{2}$ score is also indicated on each panel, calculated from decadal averages between 2000 and 2100 (about 40 data points if all RCPs are available). The data are retrieved as the closest model grid cell from the geographical coordinates $\left[40.5^{\circ} \mathrm{N}, 73.5^{\circ} \mathrm{W}\right]$.

on the corresponding gravitational self-attraction and loading effects (Gordeev et al., 1977). We account for gravitational effects by solving the sea level equation with the same model as Bamber and Riva (2010). This approach includes self-gravitation, changes in Earth rotation, shoreline migration and elastic crustal uplift.

Our MGIC model (Eq. 1) only describes a global MGIC melt volume. To solve the sea level equation, we assume a fixed spatial melt distribution based on a recent regionally differentiated 21st century model projection (Radic and Hock, 2011, thereafter RH11). We therefore created a MGIC gravitational "fingerprint", which describes the regional sea level deviations in percent from the global mean MGIC contribution. The fingerprint is then scaled by the global MGIC contribution as calculated from Eq. (1).

Our fingerprint aggregates the effect of glacier melt in 12 world regions, including the Antarctic Peninsula. The latter accounts for the entire Antarctic MGIC projections from 
Table 2. Summary of uncertainty components accounted for in the Monte Carlo scheme. All uncertainties are combined using Monte Carlo sampling of the parameter distributions and model ensembles (10000 samples). When not indicated otherwise, the ranges indicate \pm 1 s.d.; SMB stands for surface mass balance.

\begin{tabular}{lll}
\hline Component & Description & Range \\
\hline Temperature and ocean heat uptake & MAGICC ensemble (Bayesian approach) & 600 model versions (K and J, respectively) \\
Global mean thermal expansion & Scaling vs. ocean heat uptake & $11.2 \pm 1.2 \times 10^{-23} \mathrm{~mm} \mathrm{~J}^{-1}$ \\
Dynamic sea level & GCM spatial "fingerprints" & 20 fingerprints $\left(\mathrm{mm} \mathrm{K}^{-1}\right)$ \\
Global mean MGIC (Eq. 1) & Global SMB sensitivity $b_{0}$ & $0.8 \pm 0.2 \mathrm{~mm} \mathrm{yr}^{-1} \mathrm{~K}^{-1}$ \\
- & Total volume $V_{0}$ & $410 \pm 30 \mathrm{~mm}$ \\
- & Pre-industrial temperature $T_{0}$ (ref. 1951-1980) & $-0.43 \pm 0.05 \mathrm{~K}^{-1}$ \\
Ice sheets: semi-empirical (Eq. 2) & Sea level sensitivity a & $5.6 \pm 0.4 \mathrm{~mm} \mathrm{yr}^{-1} \mathrm{~K}^{-1}$ \\
- & Fast response term $b$ & $-66 \pm 16 \mathrm{~mm} \mathrm{~K}^{-1}$ \\
- & Pre-industrial temperature $T_{0}$ (ref. 1951-1980) & $-0.43 \pm 0.05 \mathrm{~K}$ \\
- & AIS/GIS partition & $1 / 3-2 / 3$ (uniform) \\
Ice sheets: IPCC AR4+ & Polynomial fit between temperature and GIS SMB & 72 polynomial fits (mm yr ${ }^{-1} \mathrm{~K}^{-1}$ ) \\
\hline
\end{tabular}
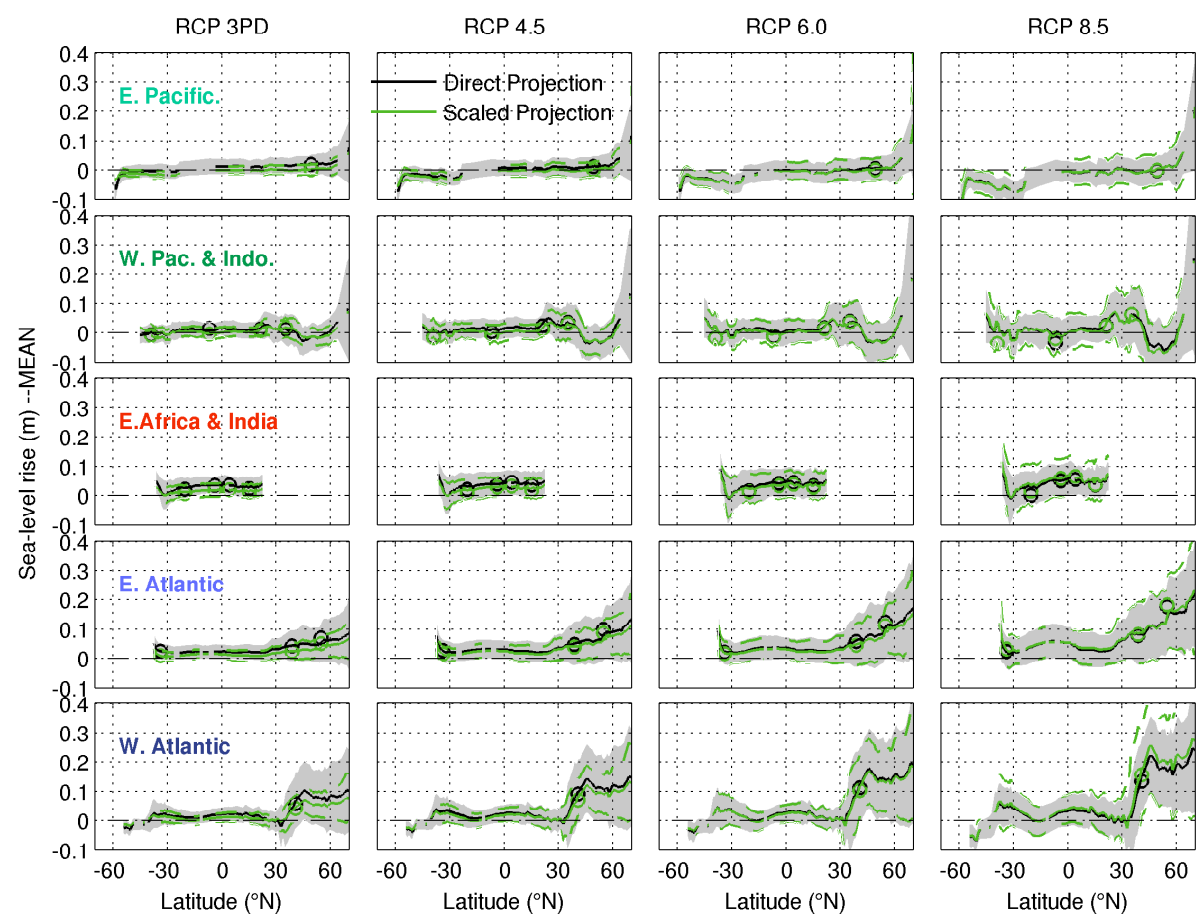

Fig. 3. Comparison between direct (black lines with grey shading) and scaled (green, solid lines with dashed envelope) dynamic sea level projections along coastlines (see explanations for the coastlines in the legend of Fig. 9), for the RCP scenarios 3PD, 4.5, 6.0 and 8.5 (from left to right panels). Solid lines indicate multi-model mean of the projections and the envelopes represent one standard deviation. The circles represent locations first introduced in Fig. 9. Note that the scaled projections are always based on the same regression pattern derived from all combined RCP scenarios. The projections are between 1980-1999 and 2090-2099 averages.

RH11, ignoring potential contributions from around the margins of the East Antarctic, where temperatures are expected to remain cold during the projection period. Note that we do not model the 7 regions of RH1 that are projected to individually cause less than $1 \mathrm{~mm}$ SLR by 2100 , together accounting for about $1 \%$ of the total MGIC contribution. An overview of the MGIC regions retained to derive the fingerprint can be found in Fig. 4a.
We then test the sensitivity of our MGIC fingerprint to the distribution of MGIC mass loss. For that purpose, we compare regional estimates of present-day MGIC melt (based on a synthesis from Bamber and Riva (2010), except for Asian high mountains, which is based on Jacob et al. (2012)) with simulated MGIC loss from RH11 (Fig. 4a), and compute the corresponding gravitational fingerprints (Fig. 4b and c). In addition to the 21 st century projections, from 


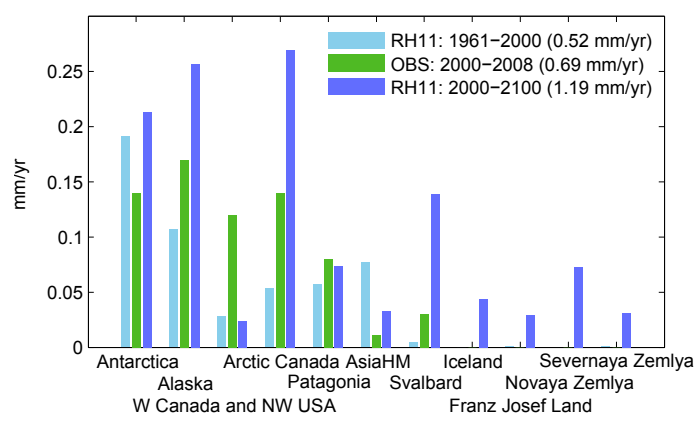

(a) Regional MGIC melt: observed and simulated

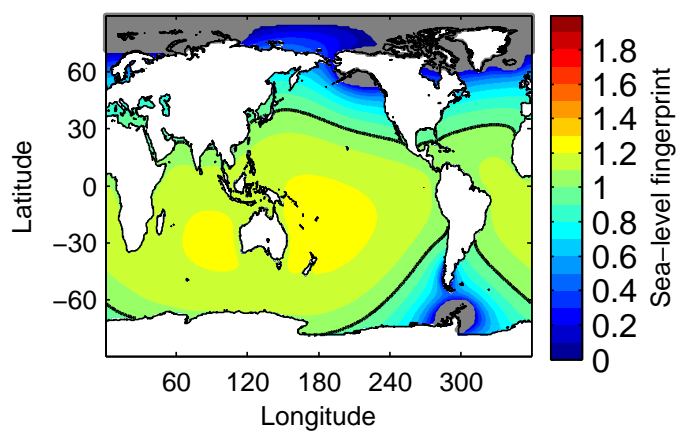

(b) MGIC fingerprint: after RH11 model projections

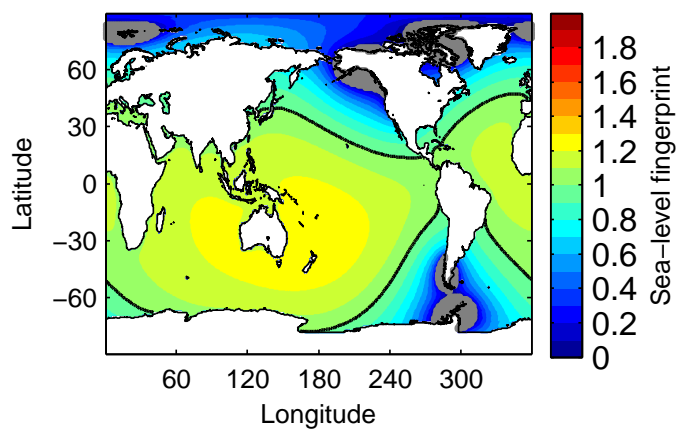

(c) MGIC fingerprint: after present-day observations

Fig. 4. (a) MGIC contribution to SLR as simulated for the past 1961-2000 period (RH11) (light blue), observed over the recent 2000-2008 period (see text) (green) and projected over the 20002100 period (RH11) (dark blue). (b, c) Corresponding MGIC gravitational fingerprints computed after (b) RH11 model projections (the fingerprint used in this study) and (c) observations. The thick black line indicates the global mean sea level change. Gray areas indicate a sea level fall.

which we derived our MGIC fingerprint, we also show the results of an hindcast of the 1960-2000 period from the same RH11 model (Fig. 4a) (RH11 data were obtained from their Table S6).

Projected losses in RH11 for the Rocky Mountains and Western Canada are much less than present-day estimates (Fig. 4a), meaning possible overestimation of sea level rise in these regions if the current rate is accurate and sustained (due to the underestimated gravitational effects, which cause sea level to drop in the proximity of melting ice masses) (Fig. $4 \mathrm{~b}$ and c). On the other hand, Arctic glaciers have large projected contributions to SLR, whereas both current observations (Bamber and Riva, 2010, and references therein) and simulations of the past 1960-2000 period (RH11) indicate no significant contribution to global SLR (Fig. 4a). We interpret the latter as a robust indication of a likely increasing contribution from MGIC in northern high-latitude regions during the 21 st century, which motivated us to use projected rather than present-day mass loss patterns to generate the 21 st century MGIC fingerprint (Fig. 4b).

\subsection{Ice sheets}

The potentially large, but uncertain (Lowe and Gregory, 2010; Rahmstorf, 2010) contributions by the two big ice sheets (on Greenland and Antarctica) warrants applying a range of approaches. Here we intend to reflect two categories of projections most commonly found in the literature, namely "process-based" projections like those of the last IPCC report (Meehl et al., 2007b), and semi-empirical projections (Rahmstorf, 2007). These two approaches translate into a low and a high SLR scenario.

\subsubsection{IPCC AR4 ${ }^{+}$(Low)}

Our low estimate of ice sheet wastage assumes IPCC AR4like SLR contributions (referred to as IPCC $\mathrm{AR}^{+}$) where only Greenland's surface mass balance contributes to the global mean SLR (Meehl et al., 2007a).

We randomly combined our 600 MAGICC6 GMT projections with 72 polynomial fits ${ }^{1}$ of GIS's surface mass balance as a function of GMT change (Gregory and Huybrechts, 2006). The polynomials were derived for the AR4 using various global and regional GCM simulations with a degree-day surface mass balance model.

In the AR4, it was assumed that Antarctica could also gain mass under global warming conditions, due to an acceleration of the hydrological cycle and increased precipitation onto the ice sheet. At that time, process-based models were unable to represent ice-ocean interactions, although oceaninduced basal melting is thought to be a major driver of present (Pritchard et al., 2012) and future (Hellmer et al., 2012) changes. Considering these missing processes, and given recent observations (Rignot et al., 2011) and modeling results (Winkelmann et al., 2012), we posit that a net mass gain of the AIS appears unlikely and we thus set the lower bound for the AIS contribution in the 21st century to zero.

A range of $0.6-4.5 \mathrm{~cm}$ has recently been proposed for GIS's dynamic contribution to SLR by 2100 , based on a 3D ice sheet model (Price et al., 2011). We acknowledge this

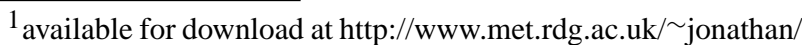
data/ar4_ice_sheet_smb.html
} 
contribution, but the dependency on temperature for the upper part of the range is unclear, and the lower bound $0.6 \mathrm{~cm}$ is not significantly different from zero when put in the context of total SLR. Other attempts to model GIS dynamic contributions (Graversen et al., 2010; Seddik et al., 2012) make use of artificial sliding enhancement at the base of the icebedrock interface. These can lead to large dynamic ice sheet contributions (e.g. $13 \mathrm{~cm}$ in Seddik et al., 2012) but it is unclear whether such a forcing can be physically justified based on our current understanding of GIS dynamics. We therefore decided not to include any GIS dynamic contribution in our low "process-based" estimate.

\subsubsection{Semi-empirical (High)}

Our high estimate is a "top-down" approach, where global SLR projections are computed directly using a semiempirical model (Rahmstorf et al., 2011) calibrated with past variations of observed global mean sea level and GMT. The GIS and AIS projections are then taken as the residual from the semi-empirical total SLR projections minus the steric and the MGIC contributions. Given the large uncertainties, we assume a simplified partitioning between GIS and AIS by varying the GIS/AIS loss ratio uniformly between $1 / 3$ and $2 / 3$ (Table 2). This is roughly consistent with recent observations (Bamber and Riva, 2010; Rignot et al., 2011), and turns out not to be critical for projected low- to mid-latitude SLR (see Sect. 4.1 below).

Semi-empirical methods are based on simple physical considerations and exploit a relationship between global mean sea level and surface temperature (or radiative forcing) in the observational record to project future SLR (Grinsted et al., 2009; Rahmstorf, 2007; Vermeer and Rahmstorf, 2009). A caveat in their application is that the semi-empirical relationship between temperature and sea level variations is calibrated over a relatively narrow range of global mean temperature variation compared to the projected warming by 2100 (Lowe and Gregory, 2010). In particular, we note that during the calibration period, the ice sheets' contribution was small compared to thermal expansion and MGIC melt. However, in the absence of robust physical models that can reliably and explicitly simulate ice sheet response to warming based on first principles, semi-empirical methods still provide a useful, plausible alternative estimate (Rahmstorf, 2010). An illustration for this is the suggested "most-likely" starting point of $0.8 \mathrm{~m}$ for 21 st century SLR from Pfeffer et al. (2008), based on extrapolation of present trends and glacio-dynamical constraints. This value is in reasonable agreement with semiempirical projections (see Sect. 3.1). More in-depth discussion and robustness tests can be found in Rahmstorf et al. (2011).

Global mean sea level projections are computed after Rahmstorf et al. (2011), which is a slightly modified version of the Vermeer and Rahmstorf (2009) model, where the rate of sea level change $\mathrm{d} H / \mathrm{d} t$ is assumed to be proportional to the temperature anomaly relative to a pre-industrial equilibrium $T_{o}$. An additional term proportional to the derivative of global mean temperature $\mathrm{d} T / \mathrm{d} t$ captures the rapid response of sea level to temperature variations, related to mixed-layer dynamics. Therefore:

$$
\frac{\mathrm{d} H}{\mathrm{~d} t}=a\left(T-T_{o}\right)+b \frac{\mathrm{d} T}{\mathrm{~d} t},
$$

where $a$ and $b$ are regression coefficients (see Table 2 for parameter values and their uncertainty ranges). Sea level time series (Church and White, 2006) are corrected for artificial reservoir impoundment (building of dams) (Chao et al., 2008) and ground-water mining (Konikow, 2011) before the regression, so that we only account for climate-induced changes in sea level.

The statistical approach is detailed in Rahmstorf et al. (2011), which accounts for autocorrelation in the residual time series and the correlation between model parameters. Here, we further inflate the projected uncertainty range by a factor of two to account for errors other than formal fitting of the model, such as data error and model choice. Furthermore, we do not extrapolate future groundwater pumping as is done in Rahmstorf et al. (2011). Note that our projections up to 2100 are consistent with semi-empirical projections calibrated with proxy data from the past $1000 \mathrm{yr}$ (Kemp et al., 2011; Rahmstorf et al., 2011; Schaeffer et al., 2012).

\subsubsection{Ice sheet gravitational signature}

The AIS and GIS regional fingerprints (Fig. 5c and d) are obtained similarly to the MGIC fingerprint (see Sect. 2.2.2), but accounting for the present-day distribution of mass loss as observed from satellites (Bamber and Riva, 2010). This spatial distribution of the mass loss region might change in the future, but the influence on sea level patterns is only important in the very near-field of an ice sheet $(<1000 \mathrm{~km})$, and is negligible further away for all practical purposes (Fig. 3 in Bamber and Riva, 2010; Farrell and Clark, 1976).

\subsection{Uncertainty characterization}

Our scaling approach is designed to provide an uncertainty estimate of future regional sea level changes, combining the uncertainties attached to each individual component. Table 2 summarizes uncertainty ranges which were sampled in our Monte Carlo approach. For the global mean SLR projections, they include uncertainties in global temperature and ocean heat uptake projections (MAGICC6), in the scaling coefficient from ocean heat uptake to global mean thermal expansion (CMIP5 GCMs), in MGIC parameters of Eq. (1), in semi-empirical model coefficients (modified after literature) and in polynomial coefficients to derive GIS surface mass balance from global mean temperature (IPCC AR4). For the regional patterns, uncertainties are quantified by the set of 20 "dynamic fingerprints" derived from CMIP5 GCMs - the 
Table 3. Global mean projected contributions between 1980-1999 and 2090-2099 periods. Brackets indicate the "likely" range (roughly the 16th and 84th percentiles). The unit is centimetre or degree Celsius. All numbers are rounded. Note that mountain glaciers and ice caps (MGIC) include those present at Greenland margins and on the Antarctic Peninsula.

\begin{tabular}{|c|c|c|c|c|c|c|c|}
\hline Scenario & Ice sheet case & $\begin{array}{c}\text { Thermal } \\
\text { expansion }(\mathrm{cm})\end{array}$ & MGIC (cm) & GIS (cm) & AIS (cm) & Total (cm) & $\begin{array}{c}\text { Global mean } \\
\text { temperature }\left({ }^{\circ} \mathrm{C}\right)\end{array}$ \\
\hline \multirow[t]{2}{*}{ RCP 3-PD } & IPCC AR4 $^{+}$ & $16(11,23)$ & $12(9,16)$ & $2(1,3)$ & $0(0,0)$ & $30(24,39)$ & $1.1(0.8,1.4)$ \\
\hline & Semi-empirical & & & $22(14,34)^{*}$ & $23(14,34)^{*}$ & $75(59,94)$ & \\
\hline \multirow[t]{2}{*}{$\mathrm{RCP} 4.5$} & IPCC AR4 ${ }^{+}$ & $22(15,31)$ & $14(10,18)$ & $3(2,4)$ & $0(0,0)$ & $39(31,49)$ & $2.0(1.6,2.5)$ \\
\hline & Semi-empirical & & & $24(13,38)^{*}$ & $24(14,39)^{*}$ & $86(66,111)$ & \\
\hline \multirow[t]{2}{*}{ RCP 6.0} & IPCC AR4 $^{+}$ & $24(16,33)$ & $14(10,19)$ & $3(2,4)$ & $0(0,0)$ & $42(33,52)$ & $2.6(2.1,3.3)$ \\
\hline & Semi-empirical & & & $23(12,37)^{*}$ & $23(12,37)^{*}$ & $86(66,110)$ & \\
\hline \multirow[t]{2}{*}{ RCP 8.5} & $\mathrm{IPCC} \mathrm{AR}^{+}{ }^{+}$ & $33(22,45)$ & $17(13,23)$ & $4(3,8)$ & $0(0,0)$ & $56(44,70)$ & $4.3(3.5,5.5)$ \\
\hline & Semi-empirical & & & $27(12,48)^{*}$ & $27(12,48)^{*}$ & $106(78,143)$ & \\
\hline
\end{tabular}

* indicate that ice sheet contributions are obtained from the semi-empirical approach (see main text)

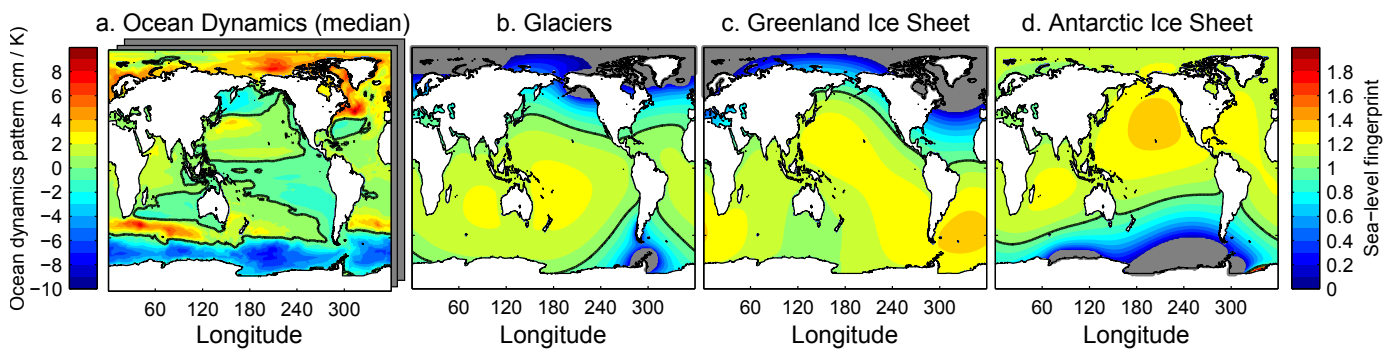

Fig. 5. (a)Sea level fingerprints for ocean dynamics (median), (b) mountain glaciers and ice caps, (c) GIS and (d) AIS, expressed in unit of regional sea level rise per unit of global mean temperature change (a) or global mean contribution of the source used for scaling (b-d). Note that only the median of the 20 temperature-dependent ocean dynamic anomaly patterns is shown in (a). All of the 20 patterns, as derived from CMIP5 GCMs, are shown in Fig. S2 in the Supplement. The ocean dynamic pattern in (a) is scaled by temperature projections and then added to the global mean thermal expansion (see main text) while mass additions from land ice are used to scale the gravitational patterns. The thick black line corresponds to the global mean on all maps, and grey shading indicates areas of sea level drop.

scaling from global mean temperature to regional dynamic sea level changes - and by combining 3 land ice fingerprints: MGIC, GIS and AIS.

Next to these formal uncertainties, which provide error bars on projections under a number of assumptions, e.g. emission and ice sheet scenarios, we also attempt to quantify uncertainties arising from any deviation from these assumptions. This is done by considering a range of scenarios (RCP scenarios, low and high ice sheet cases) and by discussing the impacts of certain assumptions, such as the ocean dynamic scaling (Sect. 2.1.2), the distribution of ice mass loss (Sects. 2.2.2 and 4.2), the GIA (Sect. 4.3) or ocean-ice sheet feedbacks (Sect. 4.6). In particular, we treat both ice sheet scenarios separately since it is not possible to formally assess which outcome - if any - is more likely. On the other hand, we aggregate CMIP5 GCM projections as equally likely, and express the resulting range as percentiles (e.g. the $67 \%$ "likely" range), as was done in the IPCC AR4 and Frieler et al. (2012). We note, however, that a sample of GCMs may underestimate the full uncertainty range partly because of tuning to the same observations, thus due caution in the interpretation of the uncertainties in this regard is advised.

\section{Results}

\subsection{Global mean contributions}

GMT increases over the 21 st century are projected to be approximately four times higher under RCP 8.5, compared to the lowest scenario, RCP 3-PD (see Table 3). In contrast, ocean thermal expansion varies only within a factor of two across the RCPs, from $16 \mathrm{~cm}(11-23 \mathrm{~cm})$ to $33 \mathrm{~cm}(23-$ $45 \mathrm{~cm})$, reflecting the higher thermal inertia of the ocean in comparison to the atmosphere (due to the timescale of downward heat mixing, which is on the order of several hundred years), which effectively delays much of the equilibrium heat uptake into centuries to come. Our global mean MGIC calculations yield a somewhat narrower range - partly due to the volume area scaling effect - ranging from $12 \mathrm{~cm}(9-16 \mathrm{~cm})$ for RCP 3-PD to approximately $50 \%$ higher projections, i.e. $17 \mathrm{~cm}(13-23 \mathrm{~cm})$, for RCP 8.5 . The two different sensitivity cases to quantify the contributions from GIS and AIS 


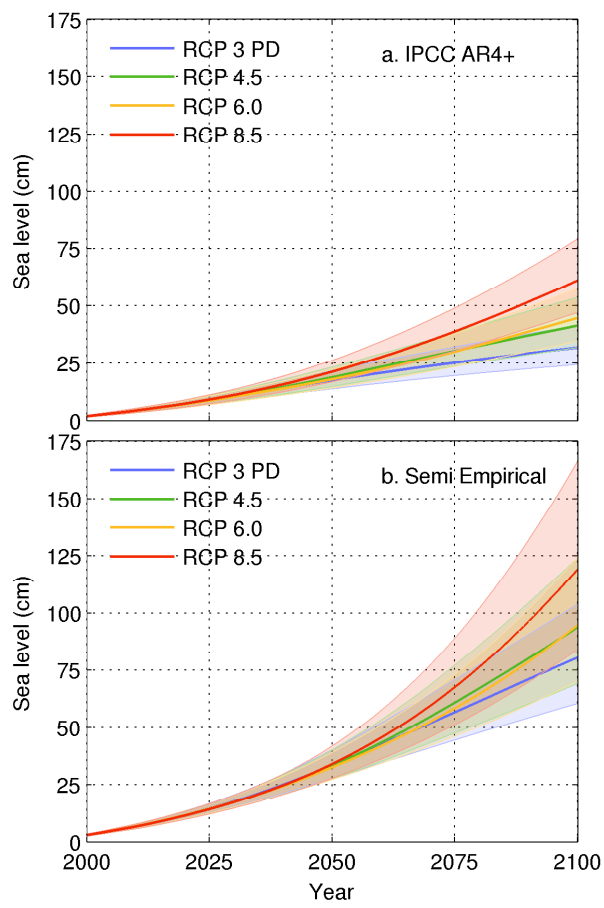

Fig. 6. Projected global mean sea level rise during the 21 st century for the four RCP scenarios, in (a) the IPCCAR4 ${ }^{+}$case and (b) the semi-empirical case. The shading indicates the likely range (16th to 84th percentiles).

over the 21 st century differ markedly. Our semi-empirical sensitivity case yields a maximum of $27 \mathrm{~cm}(12-48 \mathrm{~cm})$ for each ice sheet under RCP 8.5, whereas in the IPCC AR4 ${ }^{+}$ case, GIS contribution reaches only $4 \mathrm{~cm}(3-8 \mathrm{~cm})$.

The inter-scenario range is comparable in both ice sheet approaches despite the large differences in total ice sheet contributions: the RCP 8.5 scenario is $26 \mathrm{~cm}$ higher than the RCP 3PD scenario in the IPCCAR4 ${ }^{+}$case, and $31 \mathrm{~cm}$ higher in the semi-empirical case. However, the apparent robustness of this result depends on the underlying assumptions of the projections and thus caution is required in its interpretation. In particular, we cannot exclude that the risk of ice sheet destabilization, represented in our approach by the high semi-empirical scenario, may have a greater dependency on the actual degree of warming than what is implied here. Therefore, while it is useful to consider the risk of meter-scale SLR, we may still underestimate the benefit of mitigation on 21 st century SLR. Note that a sensitivity test with the simple model from Rahmstorf (2007) (that is, $b=0$ ) leads to $\sim 10 \mathrm{~cm}$ lower RCP 3PD projection while the RCP 8.5 projection remains unchanged (see also Fig. 12 in Rahmstorf et al., 2011).

Global mean sea level projections up to 2050 are relatively independent of the particular RCP scenario, and start to diverge only in the second half of the 21st century (Fig. 6a).

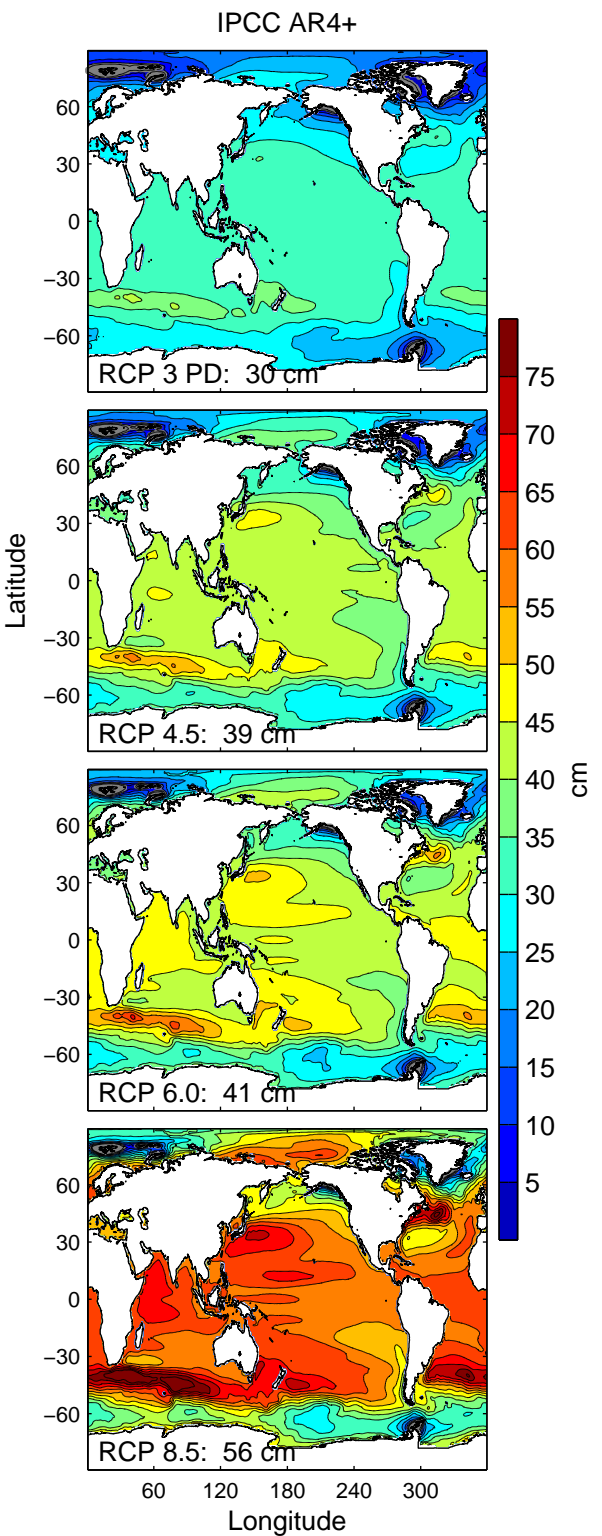

Fig. 7. Projected median regional sea level change for all RCP scenarios (from RCP 3PD to RCP 8.5) in the IPCCAR4 ${ }^{+}$ice sheet case. Contour lines are every $5 \mathrm{~cm}$. Grey shading indicates areas of sea level drop.

SLR projections from different ice sheet approaches, however, are already distinctly different by 2025 (Fig. 6b).

\subsection{Coastal projections}

In this section we focus on the median projections, and we address the associated uncertainties in the discussion below. The median sea level pattern is very similar for various emission scenarios (Figs. 7, 8, and S5 in the Supplement), because the ratios of the various SLR contributions are approximately constant across the scenarios (cf. Table 3 and Sect. 3.1). 


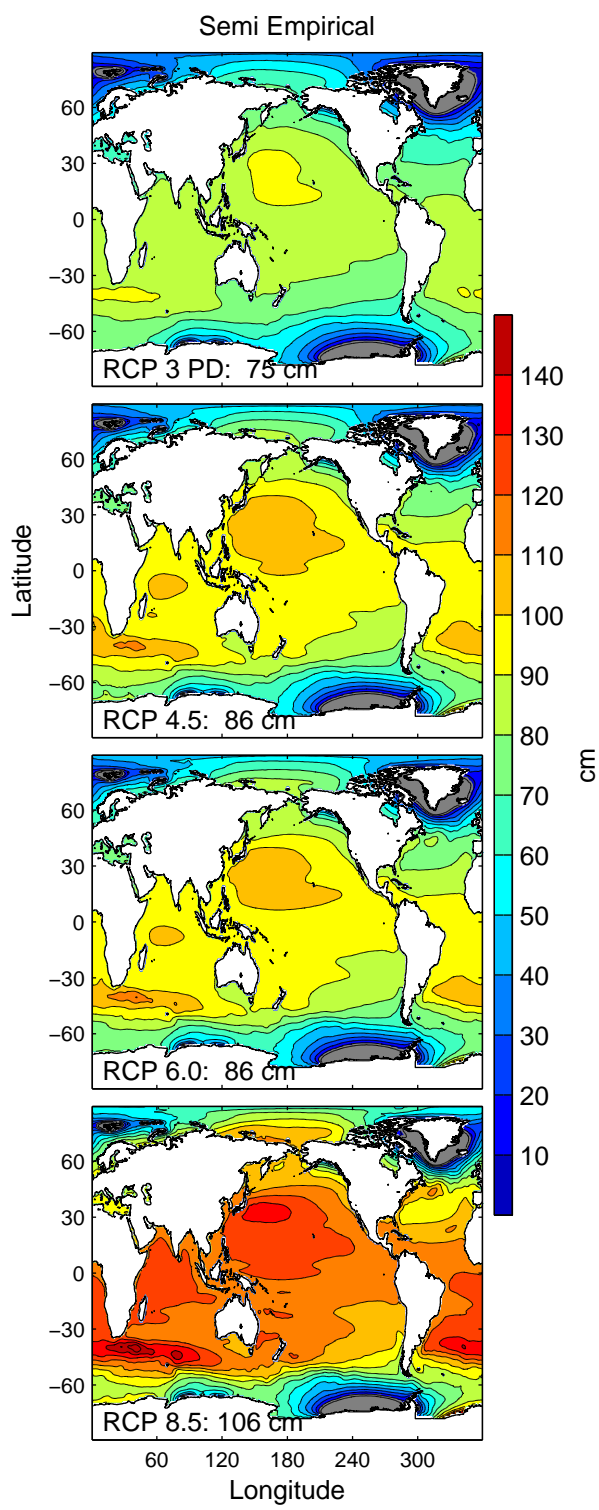

Fig. 8. Projected median regional sea level change for all RCP scenarios (from RCP 3PD to RCP 8.5) in the semi-empirical ice sheet case. Contour lines are every $10 \mathrm{~cm}$. Grey shading indicates areas of sea level drop. Note the colour scales is different from Fig. 7.

The main consistent features are above-average rise at low latitudes, in particular in the Western Pacific and Indian Ocean, and reduced rise at high latitudes (Fig. 9). We find regional variations up to $20 \%$ higher than the mean along the east Asian coast and in the Indian Ocean, and up to $30 \%$ lower than the mean in mid-latitude Northern America and Europe $\left(30-50^{\circ} \mathrm{N}\right)$. Close to the main ice melt sources (Greenland, Arctic Canada, Alaska, Patagonia and Antarctica), crustal uplift and reduced self-attraction cause below-average rise, and even a sea level fall in the very nearfield of a mass source. Through this mechanism, and due to the proximity of the Patagonian and West Antarctic glaciers,
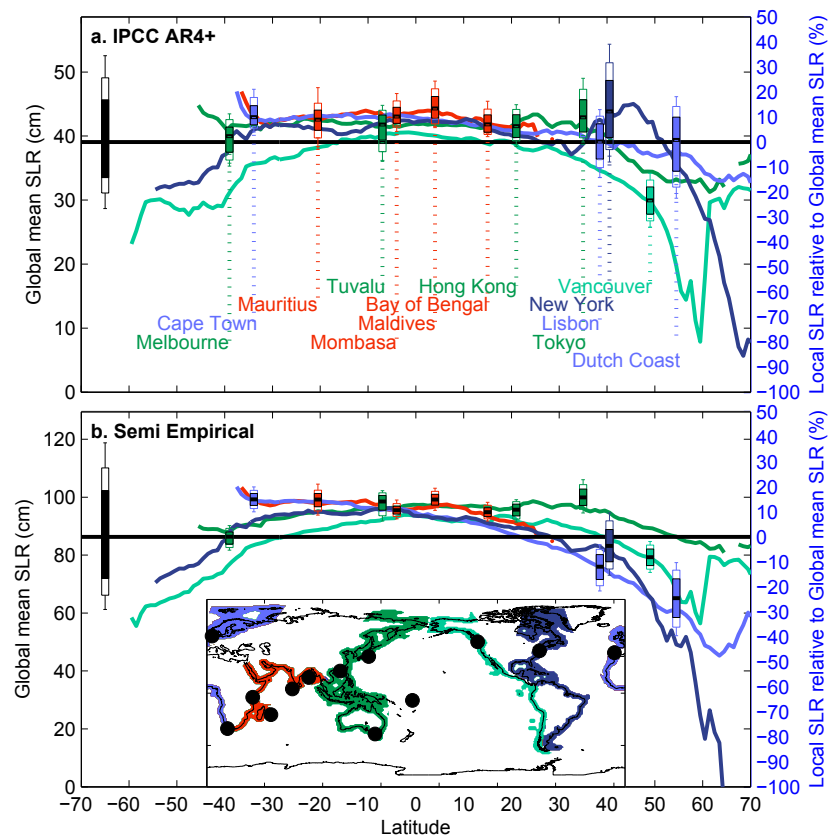

Fig. 9. Projected total sea level rise along world coastlines. Coloured lines show regional sea level projections, averaged over coastal areas ( $<300 \mathrm{~km}$ from land), and for various ocean basins (see inlet for coastlines). Global mean SLR $(\mathrm{cm})$ is indicated by a horizontal black bar on the left for each scenario, with 50, 67 and $80 \%$ uncertainty ranges. Particular locations are also shown (black dots on the inlet map, and vertical dashed lines). The uncertainty ranges for these only describe the relative deviation from the global mean $(\%)$, to highlight uncertainty in regional fingerprints. The total uncertainty in regional sea level (shown in Fig. S5 in the Supplement for all RCP scenarios) is a combination of local (right y-axis) and global (left y-axis) sea level uncertainties.

high-latitude South America experiences sea level change up to $30 \%$ below the global mean.

The projected SLR pattern is the result of the interplay between steric and mass contributions, which both have strong regional signatures at high latitudes (Fig. 10). In the IPCC AR4 ${ }^{+}$case, the MGIC near the poles compensates for the small ice sheet contributions in terms of gravity changes. However a number of differences in the patterns remain between the two ice sheet cases. In the Northern Hemisphere, particularly in the North Atlantic, mass and steric contributions act in opposite directions: below-average ice contributions partly (IPCC AR4 ${ }^{+}$, Fig. 9a) or fully (semi-empirical, Fig. 9b) offset strong dynamic SLR along the East Coast of the USA (Yin et al., 2009; Kopp et al., 2010). This contrasted pattern is mostly due to Greenland contribution and to the associated gravitational depression in the North Atlantic, which is less significant in the IPCC $\mathrm{AR}^{+}$case. In the North Pacific, relative sea level in the IPCC AR4 ${ }^{+}$case is lower due to the lack of Antarctica contribution and of its above-average regional, gravitational signature. Moreover, Alaskan glacier retreat and its effects along the northwestern American coast 

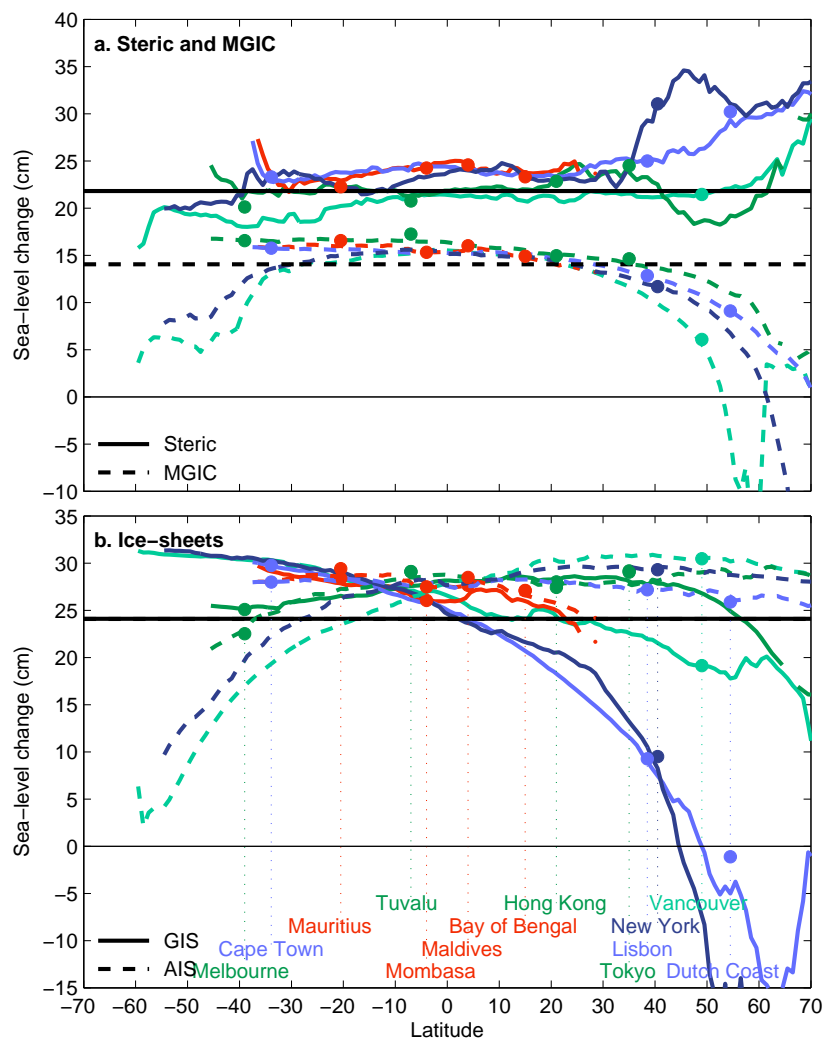

Fig. 10. Projected contributions to sea level rise along world coastlines for the RCP 4.5 scenario. (a) Solid coloured lines show regional sea level change due to steric expansion and dashed lines the MGIC melt; and (b) ice sheets wastage (GIS: solid line, AIS: dashed line) in the semi-empirical case, averaged over coastal areas, and for various oceans. Global mean contributions $(\mathrm{cm})$ are indicated by a thick horizontal black line (see also caption of Fig. 9 for more details).

near Vancouver contribute to the lower relative SLR in the IPCC AR4 ${ }^{+}$case.

North of $55^{\circ} \mathrm{N}$, the sum of mass and steric contributions is below average along all coastlines. At lower latitudes, the deviations from the global mean are smaller but tend to be of the same sign, with an overall above-average SLR (Fig. 10).

A selection of four world's locations (Fig. 11) shows how the contributions to SLR may vary over space and time in the high ice sheet scenario. It is noteworthy that land ice is projected to represent about two thirds of future SLR in the Bay of Bengal, while its contribution is only about half along the Dutch Coast, mostly due to gravitational effects which effectively suppress the GIS contribution there. Ocean steric expansion (as the sum of global mean thermal expansion and local dynamic effects) also varies significantly, with $33 \mathrm{~cm}$ rise in the New York City region and $23 \mathrm{~cm}$ rise in the Bay of Bengal. In this example, the contribution of Glacial Isostatic Adjustment (GIA) was included (based on ICE-5G, VM2, Peltier, 2004) to enable comparison with the other
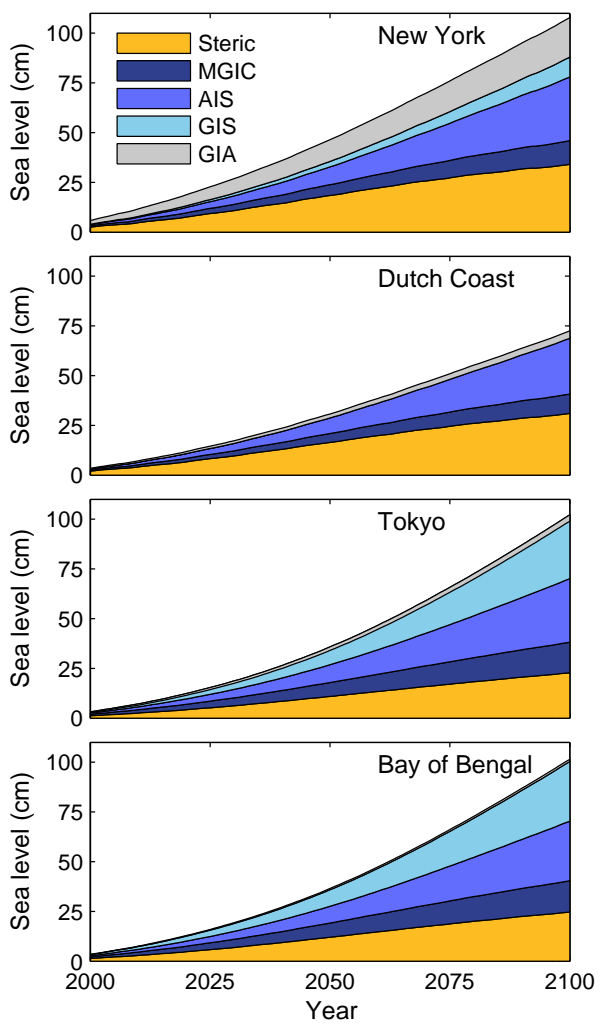

Fig. 11. Projected median contributions to sea level rise during the 21 st century, around four coastal locations for the semi-empirical case, under the RCP 4.5 scenario. Each colour represents a contribution to sea level rise. In this example, the glacial isostatic adjustment (GIA) contribution (based on ICE-5G, VM2) has been included for comparison with the other contributions.

contributions. In New York, which is close to the former Laurentide ice sheet (during the last ice age), it is of the same order of magnitude as other contributions, whereas it is negligible further away (Tokyo and Bay of Bengal). The GIA signal is also negligible along the Dutch coast in our calculations, even though the region is not very distant from the former Fennoscandian ice sheet; however, this value is rather uncertain due to its sensitivity to the adopted ice history and Earth model (Schotman and Vermeersen, 2005). Incidentally, GIA-induced SLR is positive in the chosen locations, but can generally be of both signs (Fig. S6 in the Supplement).

\section{Discussion}

\subsection{Formal uncertainties}

In this section, we discuss the formal uncertainties associated with the regional sea level change projections, as described in the Methods (Sect. 2.4) and summarized in Table 2.

In the semi-empirical approach, where the ice sheets contribute a large fraction to the total SLR, the uncertainty in 
the ratio between local and global mean SLR is relatively small, except in the near-field of the ice sheets (Fig. 9b). These results contrast sharply with the low IPCC $\mathrm{AR}^{+}$case (Fig. 9a), where ocean dynamics are the main source of spread in projected regional SLR; the uncertainty in the SLR pattern itself may be as large as the uncertainty in the global mean SLR.

The uncertainty of regional SLR projections in the semiempirical case, excluding the immediate ice sheet surroundings, can be up to $35 \%$ greater than the global mean SLR uncertainty (Fig. 12a). The partitioning uncertainty, arising from the prescribed range of $1 / 3$ to $2 / 3$ in the GIS/AIS contributions' ratio, is very large near the ice sheets, whereas for regions further away (e.g. in the Pacific and Indian Ocean), this uncertainty is only a few centimeters (Fig. 12c) because the GIS and AIS fingerprints have similar magnitudes in these regions (Fig. 5c and d). In other words, the relative contribution of the AIS and GIS will affect local SLR only in the North Atlantic and Southern Ocean. Above-average uncertainty is also found near the Gulf Stream, the Kuroshio Current and in the Southern Ocean (Fig. 12b). These regions feature strong sea level gradients governed by ocean dynamics, and while individual GCMs tend to consistently show large changes under climate forcing for these current systems, they often disagree on the exact location of the changes as the mean pattern may already present location biases under present-day conditions.

\subsection{Sensitivity to distribution of ice mass loss}

Densely populated coasts along the Bay of Bengal are projected to experience higher-than-average rise $(+10$ to $+20 \%)$ due to the combined effect of ocean dynamics and gravity changes. This result is sensitive to glacier melt in the Himalayas and other high Asian mountains: if losses of glacial mass are greater than projected, gravitational effects would lower sea level and compensate for the dynamic rise. This rationale is applicable only if the glacier meltwater actually drains into the ocean, rather than remaining on the land near its source (e.g. by filling aquifers). On decadal and longer timescales, we anticipate that glacial meltwater discharge into the oceans will be the dominant process. Similarly to the Bay of Bengal, sea level around Cape Town rises more than the global mean due to the assumed distribution of ice loss around West Antarctica. A more uniform ice loss over the Antarctic continent would lead to local SLR closer to the global mean (Fig. 3 in Bamber and Riva, 2010). The details of the mass loss distribution over Greenland have less of an impact except very close to the ice sheet (Fig. 3 in Bamber and Riva, 2010).

\subsection{Glacial Isostatic Adjustment}

In most projections discussed here, sea level changes associated to the current GIA rates were not included because GIA

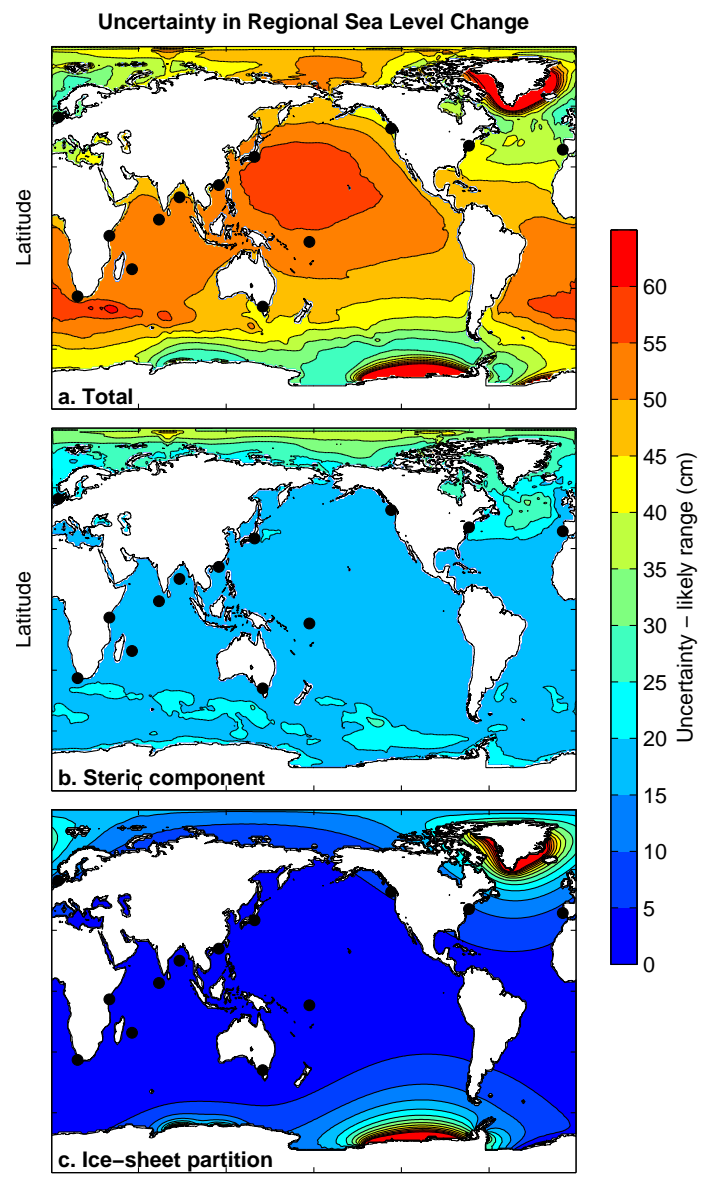

Fig. 12. (a)-(c) Uncertainty in regional sea level change, indicated as "likely" range (roughly 16th to 84th percentiles). Uncertainty in sea level change (a) and its steric component (b), for the RCP 4.5 scenario in the semi-empirical case. The uncertainty resulting from GIS/AIS partition in the semi-empirical approach is illustrated in panel (c), for a total ice sheet contribution equal to the ensemble median. Contours lines indicate $5 \mathrm{~cm}$ intervals. Black dots indicate individual locations highlighted in Fig. 9.

is independent from current and projected climatic change. The rate of this process is nearly constant on the timescales considered here (Peltier and Andrews, 1976), albeit with considerable uncertainties. The GIA contribution to global mean SLR is very small (Tamisiea, 2011), however, present-day GIA is causing significant sea level changes in many coastal areas. In particular, close to the former ice sheets, GIA effects are of the same order of magnitude as the signature of present-day ice loss (Bamber and Riva, 2010; Slangen et al., 2011) (Figs. 11, S6 and S7 in the Supplement). Considering the current limits in models of the Earth's glacial history and of the GIA process itself, it remains difficult to accurately quantify the uncertainties associated with the available GIA models. We stress that the GIA is different from the elastic crustal uplift occurring in response to melting. The former 
occurs over several millennia, while the latter is the instantaneous elastic response of the solid Earth.

\subsection{Natural variability}

In addition to the long-term changes modeled here, interannual to multi-decadal natural variability can significantly influence local sea level changes. In the Western Pacific, for example, rates of rise between 1993 and 2008 observed by satellite altimetry were twice as large as global mean SLR during the same period (Cazenave and Llovel, 2010).

Past records from tide gauges suggest that such large deviations from the global mean rise are related to climate indices such as El Niño and the Pacific Decadal Oscillation (Bromirski et al., 2011), and they likely do not reflect a long-term trend during the 20th century. GCMs simulate major modes of natural, interannual variability, but the phase and amplitude generally differ from actual observations, and the response of these modes to climate forcing during the 21 st century is even more uncertain (Collins et al., 2010). As a consequence, GCM simulations cannot presently be used to reliably project the future phase of a particular mode of natural variability, or any long-term changes in this mode. Natural-mode variability should, however, become relatively less significant as global sea level rises to the higher rates projected here.

\subsection{Comparison to earlier studies}

There are only a few studies, to our knowledge, which provide a regional assessment of sea level rise including both steric-dynamic and land ice contributions. Slangen et al. (2011) extend to the global domain sea level scenarios first investigated for the Netherlands (Katsman et al., 2011). A detailed comparison of our IPCC AR4 ${ }^{+}$case with Slangen et al.'s (2011) work (Fig. S7 in the Supplement), also including GIA, shows a consistent picture across the two approaches in most locations (qualitatively consistent regarding the sign of the regional sea level departure from the global mean SLR, and quantitatively consistent within the "likely" range), with largest discrepancies occurring in the near field of the large MGIC (e.g. Vancouver). The uncertainty estimates tend to be larger in our study due to the different treatment of the uncertainty, the different GCMs used and in particular the broader range of expected 21st century warming in MAGICC6 than in the GCMs selected in Slangen et al. (2011).

\subsection{Ice sheet discharge, ocean freshening and the northeastern North American coast}

The northeastern North American coast deserves particular attention, as the nearby Gulf Stream causes sharp sea level height gradients in the present climate (Yin et al., 2009), and tide gauges indicate that SLR rate has accelerated 34 times faster than the global mean SLR rate between 19501979 and 1980-2009 (Sallenger et al., 2012). Model studies suggest that this region might continue to experience large dynamic sea level rise in relation to Gulf Stream and Atlantic Meridional Overturning Circulation (AMOC) slowdown, largely due to the projected increase in precipitation over the North Atlantic (Yin et al., 2009; Schleussner et al., 2011), but also because of freshwater discharge from Greenland melting (Levermann et al., 2005; Kopp et al., 2010; Stammer et al., 2011).

Consistently with this body of research, our projected dynamic changes for the US northeast coast around New York are above the global mean $(\sim 10 \mathrm{~cm}$, Figs. 3 and 10a), but they are also weaker than in a previous assessment using a subset of CMIP3 GCMs $(\sim 20 \mathrm{~cm})$ (Yin et al., 2009). The projected SLR amplitude strongly depends on the choice of the members included in the GCM ensemble, whose spatial resolution and skills at reproducing local conditions can vary significantly. Moreover, large, small-scale differences in dynamic SLR are projected across the continental shelf at this location, which could lead to a different interpretation of local SLR (e.g. single grid cells vs. regional average). Another recent study (Schleussner et al., 2011) projected sea level rise around New York City based on expected AMOC slowdown under future climate forcing, and a transfer function between AMOC and SLR obtained from Yin et al. (2009). They obtain a dynamic rise of similar magnitude than the present paper for the RCP 4.5 scenario. Slangen and colleagues (2011) estimated future SLR in the SRES A1B scenario to be globally largest in the New York City region (about $19 \mathrm{~cm}$ above the global mean). In their study, however, the main contribution at this location comes from GIA, which we do not include here (see Sect. 4.3 and Figs. 11, S6 and S7).

The regional sea level projections described so far do not include the ocean's dynamic response from the additional freshening due to Greenland and Antarctic meltwater discharge (e.g. Levermann et al., 2005; Kopp et al., 2010; Stammer et al., 2011; Lorbacher et al., 2012), because oceans and ice sheets were not interactively coupled in the CMIP5 simulations. A slowdown of the AMOC in response to Greenland's freshwater forcing may result in enhanced (up to $10 \mathrm{~cm})$ SLR along the northeastern North American coast (Stammer et al., 2011). Schleussner et al. (2011), in a simplified setting, calculated that a Greenland SLR contribution of $20 \mathrm{~cm}$ could reduce the AMOC by $10 \%$, and lead to roughly $4 \mathrm{~cm}$ additional dynamic SLR around New York City, somewhat less than Stammer et al. (2011).

In that area, reduced gravitational pull from melting Greenland offsets about $60 \%$ of its contribution to SLR (Fig. 10b), leading to a rise of about 2 to $15 \mathrm{~cm}$ less than the global average from this source in the low and high ice sheet scenarios, respectively. In comparison, MGIC melt causes sea level to rise $3 \mathrm{~cm}$ less than the global average, and Antarctica up to $5 \mathrm{~cm}$ more than the global average. Therefore, if Greenland's contribution is large, gravity effects may offset the dynamic rise and yield near-global average SLR in that area, as already noticed by Kopp et al. 
(2010). However, uncertainties remain in the dynamic response of the ocean to climate forcing and in the relative SLR rate from GIA (Sect. 4.3). Our scaling approach can be updated to account for Greenland melting-induced AMOC changes, but requires a set of ensemble simulations that interactively couple the ice sheets to the GCM. Alternatively, a workaround solution could consist of additional, AMOCspecific calculation of local SLR (Yin et al., 2009; Schleussner et al., 2011), or AMOC-related "fingerprints" (Kienert and Rahmstorf, 2012).

\section{Conclusions}

We have derived regional sea level projections that result from a broad range of ocean warming, circulation changes and land ice melting during the 21 st century. Our method is designed to explore the various uncertainties of each process contributing to SLR, and to be flexible with respect to emission scenarios based on a combination of global mean contributions to sea level change and their regional "fingerprints". While these fingerprints have previously been described for the non-steric sea level contributions, we have estimated a novel dynamic ocean fingerprint from an ensemble of GCM simulations, where dynamic sea level changes are scaled by global mean temperature. We showed that temperature scaling of dynamic sea level is a good first-order approximation in an ensemble context, in particular for emission scenarios without significant mitigation. The scaling of global mean thermal expansion with ocean heat content anomaly yields excellent results for all emission scenarios.

The use of fingerprints for steric and non-steric spatial sea level variations allows us, in combination with MAGICC6 probabilistic projections, to estimate the amplitudes as well as the uncertainties of sea level changes along the world's coastlines. One of the main features of these projections is the robust, above-average rise at low latitudes, especially in the Indian Ocean and Western Pacific. The pattern is shaped by mass loss of high-latitude mountain glaciers and ice caps and low steric expansion of cold Southern Ocean sea water, and in the high ice sheet scenario by the mass loss of Antarctica's and Greenland's ice sheets.

As new component-specific SLR projections become available, our regional sea level projections can be updated within the presented framework. Estimating the Greenland and Antarctic ice sheet evolution over the coming century will be central to obtaining reliable sea level rise projections, and process-based estimates of land ice melt could and should - eventually replace the estimates of the ice sheet contributions that are currently available. The indirect semiempirical, top-down approach yields significantly higher sea level projections than previously reported (e.g. IPCC-AR4, Meehl et al., 2007a), but we note that estimates of future ice sheet contributions to SLR from semi-empirical methods remain an object of debate (Rahmstorf, 2010; Lowe and
Gregory, 2010). Regarding regional patterns, further separation of the dynamic sea level fingerprints into their underlying forcings (e.g. wind changes, freshwater fluxes) and a more elaborate functional relationship (e.g. accounting for time lags between forcing and ocean response) may lead to improved scaling relationships of this regional sea level change component.

Our projections are readily applicable to impact analysis and adaptation planning under arbitrary emission scenarios, and can be augmented by non-climatic processes such as human-induced modification of land hydrology (Konikow, 2011), local subsidence (e.g. from sediments deposition and groundwater pumping Poland and Davis, 1969) and longterm glacial isostatic adjustment. For mitigation scenarios (e.g. RCP 3PD, RCP 4.5) however, it is preferable to use ocean dynamic fingerprints, which have been derived from GCM simulations based on comparable emission scenarios, to tackle the small scenario-dependency of the scaling coefficients.

\section{Supplementary material related to this article is available online at: http://www.earth-syst-dynam.net/4/ 11/2013/esd-4-11-2013-supplement.pdf.}

Acknowledgements. We thank B. Hare, S. Raper, A. Levermann and S. Rahmstorf for discussion and comments on earlier versions of this manuscript, and M. Mengel and J. Gregory for AOGCM diagnostics. We acknowledge the World Climate Research Programme's Working Group on Coupled Modelling, which is responsible for CMIP, and we thank the climate modeling groups (listed in Table S1 in the Supplement of this paper) for producing and making available their model output. For CMIP, the US Department of Energy's Program for Climate Model Diagnosis and Intercomparison provided coordinating support and led development of software infrastructure in partnership with the Global Organization for Earth System Science Portals. M. P. was supported by the Federal Ministry for the Environment, Nature Conservation and Nuclear Safety (Germany) under the project SURVIVE 11_II_093_Global_A_SIDS_and_LDC. F. W. L.'s work was carried out at the Jet Propulsion Laboratory, California Institute of Technology, under a contract with the National Aeronautics and Space Administration. K. F. and M. M. were supported by the Federal Environment Agency for Germany (UBA) under project UFOPLAN FKZ 370841103.

Edited by: M. Huber 


\section{References}

Allen, M. R., Frame, D. J., Huntingford, C., Jones, C. D., Lowe, J. A., Meinshausen, M., and Meinshausen, N.: Warming caused by cumulative carbon emissions towards the trillionth tonne., $\mathrm{Na}$ ture, 458, 1163-1166, doi:10.1038/nature08019, 2009.

Bamber, J. and Riva, R.: The sea level fingerprint of recent ice mass fluxes, The Cryosphere, 4, 621-627, doi:10.5194/tc-4-621-2010, 2010.

Bindoff, N. L., Willebrand, J., Artale, V., Cazenave, A., Gregory, J., Gulev, S., Hanawa, K., Le Quéré, C., Levitus, S., Nojiri, Y., Shum, C. K., Talley, L. D., and Unnikrishnan, A.: Climate Change 2007: The Physical Science Basis. Contribution of Working Group I to the Fourth Assessment Report of the Intergovernmental Panel on Climate Change., chap. Observations: Oceanic Climate Change and Sea Level, Cambridge University Press, New York City, 2007.

Bouttes, N., Gregory, J. M., Kuhlbrodt, T., and Suzuki, T.: The effect of windstress change on future sea level change in the Southern Ocean, Geophys. Res. Lett., 39, L23602, doi:10.1029/2012GL054207, 2012.

Brohan, P., Kennedy, J. J., Harris, I., Tett, S. F. B., and Jones, P. D.: Uncertainty estimates in regional and global observed temperature changes : A new data set from 1850, J. Geophys. Res., 111, D12106, doi:10.1029/2005JD006548, 2006.

Bromirski, P. D., Miller, A. J., Flick, R. E., and Auad, G.: Dynamical suppression of sea level rise along the Pacific coast of North America: Indications for imminent acceleration, J. Geophys. Res., 116, C07005, doi:10.1029/2010JC006759, 2011.

Cazenave, A. and Llovel, W.: Contemporary Sea Level Rise, Ann. Rev. Mar. Sci., 2, 145-173, 2010.

Chao, B. F., Wu, Y. H., and Li, Y. S.: Impact of artificial reservoir water impoundment on global sea level, Science, 320, 212-214, 2008.

Church, J. A. and White, N. J.: A 20th century acceleration in global sea-level rise, Geophys. Res. Lett., 33, L01602, doi:10.1029/2005GL024826, 2006.

Church, J. A., White, N. J., Konikow, L. F., Domingues, C. M., Cogley, J. G., Rignot, E., Gregory, J. M., van den Broeke, M. R., Monaghan, A. J., and Velicogna, I.: Revisiting the Earth's sealevel and energy budgets from 1961 to 2008 , Geophys. Res. Lett., 38, L18601, doi:10.1029/2011GL048794, 2011.

Collins, M., An, S.-I., Cai, W., Ganachaud, A., Guilyardi, E., Jin, F.-F., Jochum, M., Lengaigne, M., Power, S., Timmermann, A., Vecchi, G., and Wittenberg, A.: The impact of global warming on the tropical Pacific Ocean and El Niño, Nat. Geosci., 3, 391-397, doi:10.1038/ngeo868, 2010.

Domingues, C. M.: Improved estimates of upper-ocean warming and multi-decadal sea-level rise, Nature, 453, 1090-1094, 2008.

Farrell, W. E. and Clark, J. A.: On Postglacial Sea Level, Geophysical J. Roy. Astron. Soc., 46, 647-667, 1976.

Frieler, K., Meinshausen, M., Mengel, M., Braun, N., and Hare, W.: A Scaling Approach to Probabilistic Assessment of Regional Climate Change, J. Climate, 25, 3117-3144, doi:10.1175/JCLI-D11-00199.1, 2012.

Gordeev, R. G., Kagan, B. A., and Polyakov, E. V.: The Effects of Loading and Self-Attraction on Global Ocean Tides: The Model and the Results of a Numerical Experiment, J. Phys. Oceanogr., 7, 161-170, doi:10.1175/15200485(1977)007<0161:TEOLAS > 2.0.CO;2, 1977.
Graversen, R. G., Drijfhout, S., Hazeleger, W., Wal, R., Bintanja, R., and Helsen, M.: Greenland's contribution to global sea-level rise by the end of the 21st century, Clim. Dynam., 37, 1427-1442, doi:10.1007/s00382-010-0918-8, 2010.

Gregory, J. M. and Huybrechts, P.: Ice-sheet contributions to future sea-level change, Philos. T. Roy. Soc. A, 364, 1709-1732, 2006.

Griffies, S. M. and Greatbatch, R. J.: Physical processes that impact the evolution of global mean sea level in ocean climate models, Ocean Model., 51, 37-72, doi:10.1016/j.ocemod.2012.04.003, 2012.

Grinsted, A., Moore, J. C., and Jevrejeva, S.: Reconstructing sea level from paleo and projected temperatures 200 to $2100 \mathrm{AD}$, Clim. Dynam., 34, 461-472, 2009.

Hellmer, H. H., Kauker, F., Timmermann, R., Determann, J., and Rae, J.: Twenty-first-century warming of a large Antarctic iceshelf cavity by a redirected coastal current, Nature, 485, 225228, doi:10.1038/nature11064, 2012.

Jacob, T., Wahr, J., Pfeffer, W. T., and Swenson, S.: Recent contributions of glaciers and ice caps to sea level rise, Nature, 482 , 514-518, doi:10.1038/nature10847, 2012.

Katsman, C. A., Hazeleger, W., Drijfhout, S., van Oldenborgh, G., and Burgers, G.: Climate scenarios of sea level rise for the northeast Atlantic Ocean: a study including the effects of ocean dynamics and gravity changes induced by ice melt, Climatic Change, 91, 351-374, 2008.

Katsman, C. A., Sterl, A., Beersma, J. J., Brink, H. W., Church, J. A., Hazeleger, W., Kopp, R. E., Kroon, D., Kwadijk, J., Lammersen, R., Lowe, J., Oppenheimer, M., Plag, H. P., Ridley, J., Storch, H., Vaughan, D. G., Vellinga, P., Vermeersen, L. L. A., Wal, R. S. W., and Weisse, R.: Exploring high-end scenarios for local sea level rise to develop flood protection strategies for a low-lying delta - the Netherlands as an example, Climatic Change, 109, 617-645, doi:10.1007/s10584-011-0037-5, 2011.

Kemp, A. C., Horton, B. P., Donnelly, J. P., Mann, M. E., Vermeer, M., and Rahmstorf, S.: Climate related sea-level variations over the past two millennia, P. Natl. Acad. Sci., 108, 11017-11022, doi:10.1073/pnas.1015619108, 2011.

Kienert, H. and Rahmstorf, S.: On the relation between Meridional Overturning Circulation and sea-level gradients in the Atlantic, Earth Syst. Dynam., 3, 109-120, doi:10.5194/esd-3-109-2012, 2012.

Konikow, L. F.: Contribution of global groundwater depletion since 1900 to sea-level rise, Geophys. Res. Lett., 38, 1-5, doi:10.1029/2011GL048604, 2011.

Kopp, R. E., Mitrovica, J. X., Griffies, S. M., Yin, J., Hay, C. C., and Stouffer, R. J.: The impact of Greenland melt on local sea levels: a partially coupled analysis of dynamic and static equilibrium effects in idealized water-hosing experiments, Climatic Change, 103, 619-625, doi:10.1007/s10584-010-9935-1, 2010.

Landerer, F. W., Jungclaus, J. H., and Marotzke, J.: Regional Dynamic and Steric Sea Level Change in Response to the IPCCA1B Scenario, J. Phys. Oceanogr., 37, 296-312, 2007.

Lemke, P., Ren, J., Alley, R. B., Allison, I., Carrasco, J., Flato, G., Fujii, Y., Kaser, G., Mote, P., and Thomas, R. H.: Climate Change 2007: The Physical Science Basis. Contribution of Working Group I to the Fourth Assessment Report of the Intergovernmental Panel on Climate Change, chap. Observations: changes in snow, ice and frozen ground, Cambridge University Press, New York City, 2007. 
Levermann, A., Griesel, A., Hofmann, M., Montoya, M., and Rahmstorf, S.: Dynamic sea level changes following changes in the thermohaline circulation, Clim. Dynam., 24, 347-354, doi:10.1007/s00382-004-0505-y, 2005.

Lorbacher, K., Marsland, S. J., Church, J. A., Griffies, S. M., and Stammer, D.: Rapid barotropic sea level rise from ice sheet melting, J. Geophys. Res., 117, 1-10, doi:10.1029/2011JC007733, 2012.

Lowe, J. A. and Gregory, J. M.: A sea of uncertainty, Nature Reports Climate Change, 42-43, 2010.

Meehl, G., Stocker, T., Collins, W., Friedlingstein, P., Gaye, A., Gregory, J., Kitoh, A., Knutti, R., Murphy, J., Noda, A., Raper, S., Watterson, I., Weaver, A., and Zhao, Z.-C.: Global climate projections, in: Climate Change 2007: The Physical Science Basis. Contribution of Working Group I to the Fourth Assessment Report of the Intergovernmental Panel on Climate Change, edited by: Solomon, S., Qin, D., Manning, M., Chen, Z., Marquis, M., Averyt, K., Tignor, M., and Miller, H., chap. 10, Cambridge University Press, Cambridge, UK and New York, NY, USA, 747845, 2007a.

Meehl, G. A., Covey, C., Delworth, T., Latif, M., McAvaney, B., Mitchell, J. F. B., Stouffer, R. J., and Taylor, K. E.: The WCRP CMIP3 multimodel dataset, B. Am. Meteorol. Soc., 88, 1383-1394, 2007b.

Meinshausen, M., Meinshausen, N., Hare, W., Raper, S. C. B., Frieler, K., Knutti, R., Frame, D. J., and Allen, M. R.: Greenhouse-gas emission targets for limiting global warming to 2 C, Nature, 458, 1158-1162, 2009.

Meinshausen, M., Raper, S. C. B., and Wigley, T. M. L.: Emulating coupled atmosphere-ocean and carbon cycle models with a simpler model, MAGICC6 - Part 1: Model description and calibration, Atmos. Chem. Phys., 11, 1417-1456, doi:10.5194/acp11-1417-2011, 2011.

Mitrovica, J. X., Tamisiea, M. E., Davis, J. L., and Milne, G. A.: Recent mass balance of polar ice sheets inferred from patterns of global sea-level change, Nature, 409, 1026-1029, doi:10.1038/35059054, 2001.

Moss, R. H., Edmonds, J. A., Hibbard, K. A., Manning, M. R., Rose, S. K., van Vuuren, D. P., Carter, T. R., Emori, S., Kainuma, M., Kram, T., Meehl, G. A., Mitchell, J. F. B., Nakicenovic, N., Riahi, K., Smith, S. J., Stouffer, R. J., Thomson, A. M., Weyant, J. P., and Wilbanks, T. J.: The next generation of scenarios for climate change research and assessment, Nature, 463, 747-756, doi:10.1038/nature08823, 2010.

Murray, T., Scharrer, K., James, T. D., Dye, S. R., Hanna, E., Booth, A. D., Selmes, N., Luckman, A., Hughes, A. L. C., Cook, S., and Huybrechts, P.: Ocean regulation hypothesis for glacier dynamics in southeast Greenland and implications for ice sheet mass changes, J. Geophys. Res., 115, F03026, doi:10.1029/2009JF001522, 2010.

Pardaens, A. K., Gregory, J. M., and Lowe, J. A.: A model study of factors influencing projected changes in regional sea level over the twenty-first century, Clim. Dynam., 36, 2015-2033, doi:10.1007/s00382-009-0738-x, 2010.

Peltier, W.: Global glacial isostasy and the surface of the ice-age Earh: the ICE-5G (VM2) Model and GRACE, Annu. Rev. Earth Planet. Sci., 32, 111-149, doi:10.1146/annurev.earth.32.082503.144359, 2004.
Peltier, W. R. and Andrews, J. T.: Glacial-Isostatic Adjustment, The Forward Problem, Geophys. J. Roy. Astron. Soc., 46, 605-646, doi:10.1111/j.1365-246X.1976.tb01251.x, 1976.

Pfeffer, W. T., Harper, J. T., and O'Neel, S.: Kinematic constraints on glacier contributions to 21 st-century sea-level rise, Science, 321, 1340-1343, doi:10.1126/science.1159099, 2008.

Poland, J. F. and Davis, G. H.: Land subsidence due to withdrawal of fluids, Rev. Eng. Geol., 2, 187-269, 1969.

Price, S. F., Payne, A. J., Howat, I. M., and Smith, B. E.: Committed sea-level rise for the next century from Greenland ice sheet dynamics during the past decade, P. Natl. Acad. Sci. USA, 108, 8978-8983, doi:10.1073/pnas.1017313108, 2011.

Pritchard, H. D., Ligtenberg, S. R. M., Fricker, H. A., Vaughan, D. G., van den Broeke, M. R., and Padman, L.: Antarctic icesheet loss driven by basal melting of ice shelves, Nature, 484 , 502-505, doi:10.1038/nature10968, 2012.

Radic, V. and Hock, R.: Regionally differentiated contribution of mountain glaciers and ice caps to future sea-level rise, Nat. Geosci., 4, 91-94, doi:10.1038/ngeo1052, 2011.

Rahmstorf, S.: A Semi-Empirical Approach to Projecting Future Sea-Level Rise, Science, 315, 368-370, 2007.

Rahmstorf, S.: A new view on sea level rise, Nature Reports Climate Change, 4, 44-45, doi:10.1038/climate.2010.29, 2010.

Rahmstorf, S., Perrette, M., and Vermeer, M.: Testing the robustness of semi-empirical sea level projections, Clim. Dynam., 39, 861875, doi:10.1007/s00382-011-1226-7, 2011.

Rignot, E., Velicogna, I., van den Broeke, M. R., Monaghan, A., and Lenaerts, J.: Acceleration of the contribution of the Greenland and Antarctic ice sheets to sea level rise, Geophys. Res. Lett., 38, L05503, doi:10.1029/2011GL046583, 2011.

Sallenger, A. H., Doran, K. S., and Howd, P. A.: Hotspot of accelerated sea-level rise on the Atlantic coast of North America, Nat. Clim. Change, 2, 1-5, doi:10.1038/nclimate1597, 2012.

Schaeffer, M., Hare, W., Rahmstorf, S., and Vermeer, M.: Longterm sea-level rise implied by $1.5^{\circ} \mathrm{C}$ and $2{ }^{\circ} \mathrm{C}$ warming levels, Nat. Clim. Change, 2, 867-870, doi:10.1038/nclimate1584, 2012.

Schleussner, C. F., Frieler, K., Meinshausen, M., Yin, J., and Levermann, A.: Emulating Atlantic overturning strength for low emission scenarios: consequences for sea-level rise along the North American east coast, Earth Syst. Dynam., 2, 191-200, doi:10.5194/esd-2-191-2011, 2011.

Schotman, H. and Vermeersen, L.: Sensitivity of glacial isostatic adjustment models with shallow low-viscosity earth layers to the ice-load history in relation to the performance of GOCE and GRACE, Earth Planet. Sc. Lett., 236, 828-844, doi:10.1016/j.eps1.2005.04.008, 2005.

Seddik, H., Greve, R., Zwinger, T., Gillet-Chaulet, F., and Gagliardini, O.: Simulations of the Greenland ice sheet 100 years into the future with the full Stokes model Elmer/Ice, J. Glaciol., 58, 427-440, doi:10.3189/2012JoG11J177, 2012.

Slangen, A. B. A., Katsman, C. A., Wal, R. S. W., Vermeersen, L. L. A., and Riva, R. E. M.: Towards regional projections of twenty-first century sea-level change based on IPCC SRES scenarios, Clim. Dynam., 38, 1191-1209, doi:10.1007/s00382-0111057-6, 2011. 
Stammer, D., Agarwal, N., Herrmann, P., Köhl, A., and Mechoso, C. R.: Response of a Coupled Ocean-Atmosphere Model to Greenland Ice Melting, Surv. Geophys., 32, 621-642, doi:10.1007/s10712-011-9142-2, 2011.

Straneo, F., Hamilton, G. S., Sutherland, D. A., Stearns, L. A., Davidson, F., Hammill, M. O., Stenson, G. B., and RosingAsvid, A.: Rapid circulation of warm subtropical waters in a major glacial fjord in East Greenland, Nat. Geosci., 3, 182-186, doi:10.1038/ngeo764, 2010.

Tamisiea, M. E.: Ongoing glacial isostatic contributions to observations of sea level change, Geophys. J. Int., 186, 1036-1044, doi:10.1111/j.1365-246X.2011.05116.x, 2011.

Taylor, K. E., Stouffer, R. J., and Meehl, G. A.: An Overview of CMIP5 and the Experiment Design, B. Am. Meteorol. Soc., 93, 485-498, doi:10.1175/BAMS-D-11-00094.1, 2012.

Vermeer, M. and Rahmstorf, S.: Global sea level linked to global temperature, P. Natl. Acad. Sci., 106, 21527-21532, doi:10.1073/pnas.0907765106, 2009.
Wigley, T. M. L. and Raper, S. C. B.: Extended scenarios for glacier melt due to anthropogenic forcing, Geophys. Res. Lett., 32, L05704, doi:10.1029/2004GL021238, 2005.

Winkelmann, R., Levermann, A., Martin, M. A., and Frieler, K.: Increased future ice discharge from Antarctica owing to higher snowfall, Nature, 492, 239-242, doi:10.1038/nature11616, 2012.

Wunsch, C., Ponte, R. M., and Heimbach, P.: Decadal Trends in Sea Level Patterns: 1993-2004, J. Climate, 20, 5889-5911, doi:10.1175/2007JCLI1840.1, 2007.

Yin, J., Schlesinger, M. E., and Stouffer, R. J.: Model projections of rapid sea-level rise on the northeast coast of the United States, Nat. Geosci., 2, 262-266, 2009.

Yin, J., Griffies, S. M., and Stouffer, R. J.: Spatial Variability of Sea Level Rise in Twenty-First Century Projections, J. Climate, 23, 4585-4607, 2010. 